NBER WORKING PAPER SERIES

\title{
EXECUTION RISK AND ARBITRAGE OPPORTUNITIES IN THE FOREIGN EXCHANGE
} MARKETS

Takatoshi Ito

Kenta Yamada

Misako Takayasu

Hideki Takayasu

Working Paper 26706

http://www.nber.org/papers/w26706

\author{
NATIONAL BUREAU OF ECONOMIC RESEARCH \\ 1050 Massachusetts Avenue \\ Cambridge, MA 02138 \\ January 2020
}

The views expressed herein are those of the authors and do not necessarily reflect the views of the National Bureau of Economic Research.

At least one co-author has disclosed a financial relationship of potential relevance for this research. Further information is available online at http://www.nber.org/papers/w26706.ack

NBER working papers are circulated for discussion and comment purposes. They have not been peer-reviewed or been subject to the review by the NBER Board of Directors that accompanies official NBER publications.

(C) 2020 by Takatoshi Ito, Kenta Yamada, Misako Takayasu, and Hideki Takayasu. All rights reserved. Short sections of text, not to exceed two paragraphs, may be quoted without explicit permission provided that full credit, including $\odot$ notice, is given to the source. 
Execution Risk and Arbitrage Opportunities in the Foreign Exchange Markets

Takatoshi Ito, Kenta Yamada, Misako Takayasu, and Hideki Takayasu

NBER Working Paper No. 26706

January 2020

JEL No. F31,G12,G14,G15,G23,G24

\begin{abstract}
With the high-frequency data of firm quotes in the transaction platform of foreign exchanges, arbitrage profit opportunities - in the forms of a negative bid-ask spread of a currency pair and triangular transactions involving three currency pairs-can be detected to emerge and disappear in the matter of seconds. The frequency and duration of such arbitrage opportunities have declined over time, most likely due to the emergence of algorithmic trading. When a human trader detects such an arbitrage opportunity and places orders for multiple transactions- two in negative spreads and three in triangular arbitrage - there is no guarantee all of those orders are fulfilled in a fraction of one second. Thus, the arbitrageur has to consider execution risk, when he/ she/it detects the emergence of such an opportunity. The novelty of this paper is to show that those arbitrage opportunities were exploitable and executable, before the mid-2000s, even considering the transactions costs and execution risk. After many algorithmic computers were allowed to be connected directly to the EBS transaction platform in the mid-2000s, the frequency of free lunch cases has declined and probabilities of successful executions of all legs for arbitrage declined. We calculate the change in the expected profit of an attempt to execute necessary transactions to reap benefits from arbitrage opportunity.
\end{abstract}

Takatoshi Ito

Columbia University

School of International and Public Affairs

Room 927 IAB (MC 3333)

420 West 118th Street

New York, NY 10027

and NBER

ti2164@columbia.edu

Kenta Yamada

University of the Ryukyus

Faculty of Global and Regional Studies 1

Senbaru, Nishihara

Okinawa 903-0213

Japan

k-yamada@tm.u-ryukyu.ac.jp
Misako Takayasu

Tokyo Institute of Technology

Department of Mathematical and Computing Sciences

School of Computing

And Institute of Innovative Research

4259, Nagatsuta-cho

Yokohama, 226-8502

Japan

takayasu@dis.titech.ac.jp

Hideki Takayasu

Sony Computer Science Laboratories

3-14-13 Higashigotanda, Shinagawa-ku

Tokyo 141-0022

Japan

and Institute of Innovative Research,

Tokyo Institute of Technology

takayasu@csl.sony.co.jp 


\section{Introduction}

In most empirical work as well as theoretical work in the foreign exchange markets just assumes "no free lunch,” or no riskless, profitable arbitrage opportunities at any point of time. If profitable arbitrage opportunities are observed in data, it is often criticized that data are either indicative quotes (no guarantee of trade commitment) or stale or time-lagged/aggregated quotes. In the 1990s and 2000s, a popular data source was the Olsen data, that are based on indicative quotes observed in the Reuter FXFX. Any work on showing the existence of the arbitrage opportunities using indicative quotes was subject to a criticism in that indicative quotes did not mean they are accepted for trading when an arbitrageur tried to exploit the opportunities. The "indicative quotes" problem was solved by using "firm quotes" that are collected from an actual trading platform. The commercially available EBS data sets collect actual quotes and deal prices since 1998 with time stamp of 1 second or finer in the EBS trading platform. All the quotes in the data set are "firm."

Ito, et al. (2012) showed that the profitable arbitrage opportunities, in the form of negative bid-ask spread and triangular arbitrage opportunities, do exist in the market. The size of the profits is larger than presumed marginal execution costs. The paper also showed that the frequency and duration of the profitable arbitrage opportunities have diminished over time, in particular after more bank computers with algorithmic trading programs were allowed to connect directly with the EBS computer in 2005. The speed of disappearance of arbitrage opportunities accelerated after 2005. By 2010, when an arbitrage opportunity arose, 80-90 percent of them disappeared within one second. It used to be the case, that is, the bank machined were allowed to be connected to the EBS matching engine, that humans with eagle eyes and quick fingers could reap the profit from the temporal inefficiencies in the market, but after mid-2000s, only super-fast computers can detect and exploit the arbitrage opportunities. The paper suggests that computers having faster CPUs and being housed next (co-located) to the EBS order-matching computer can collect profits.

It is a challenge to prove that arbitrage opportunities have been exploitable and actually exploited by quick human fingers or algorithm in the machine. One critical question is whether an arbitrage opportunity disappears due to execution of profitable trades or quote revision without trades. Put differently, the question is whether free lunch was eaten by arbitrageurs or was disappeared before being eaten. Ito, et al. (2012) gave an indirect answer. The paper showed that a moment after an arbitrage opportunity appears on screen, deal activities that would make profits from the opportunities increase. This is consistent with a view that exploitable opportunities are indeed exploited by deal activities. However, the evidence is only suggestive. An arbitrageur may have not succeeded in completing two legs, in the case of negative spreads, or three legs, in the case of triangular arbitrage, of transactions that are needed to reap profits.

This paper moves an investigation one step further by explicitly calculating the execution risk. An execution risk here means that the order by a market taker, "the arbitrageur," trying to hit a bid (or an offer) is not fulfilled either because someone else's order reaches the matching engine a 
fraction of a second earlier than the arbitrageur's order; or the firm quote is cancelled a fraction earlier the arbitrageur's order reaches the matching engine.

Suppose that the arbitrage opportunity, say the negative spread in the USD/JPY market, is detected at period $t$ (measured in the unit of one second). Namely, the best bid is higher the best offer. An arbitrageur places two orders trying to hit the firm bid and to hit the firm offer simultaneously. If both are executed, the arbitrageur reaps profits, by definition of negative spread. However, if one of the orders successfully hits a bid but fails to hit an offer, then the arbitrageur is left with an unwanted short position of the dollar. The arbitrageur has to press hitting the failed trade even at an unfavorable price. This may generate the loss. If both orders are not fulfilled, zero profit is a result. Hence it is critical to calculate the success and failure of the arbitrageur's orders to be fulfilled. This represents an execution risk.

How can a researcher make inference whether a market taker's order is fulfilled or failed? In the commercially-available EBS data, the bank identity is not disclosed. Hence, we cannot directly prove whether a bank actually hit the quote.

A crucial and very realistic assumption in this paper is that if a quote does not change or change in the favorable direction for the arbitrageur-higher bid or lowering ask-from period $t$ to period $(t+1)$, then the trade of the arbitrageur is safely assumed to have been executed. If the price moves unfavorably from $t$ to $t+1$, there are two possibilities, either the arbitrageur successfully hits the firm quote and the best quote targeted for execution disappears as a result; or the arbitrageur failed to hit the quote, due to a competitor reached earlier or the market maker withdrew earlier. For the case, the price moved unfavorably, we will introduce a success probability that is used to calculate the expected profit. Simulations are conducted to calculate the expected profits as a function of the success probability.

In case of triangular arbitrage, there are three legs of transactions involved. If all three were realized, profits are reaped; if none of the three legs is realized, zero profit/loss is a result. We need to assume some behaviors in case of incomplete triangular trades: if only one leg (order) is fulfilled, it is assumed to be unwound the position one second later; and if only two legs are fulfilled, the remaining unfulfilled leg is assumed to be executed successfully one second later. Whether the exchange rate moves or not, and when it moves, moving in a favorable or unfavorable direction, makes profits to vary. Sometimes, the execution at one second later, either unwinding or completing the triangular, will result in losses.

The main findings can be summarized as follows: Both negative bid-ask spreads and triangular arbitrage profit opportunities were frequently observed and when they emerge, they tended to last for a few seconds before 2005. Conditional on the emergence of an arbitrage opportunity, the execution risk is evaluated with the inference described above. Before 2005, the expected profits, taking into account execution risk, tended to be positive, while they become positive only when the success probability is higher for the leg where the price moved unfavorably from $t$ to $t+1$. 
Even when execution risks are defined and considered the expected profits, net of transaction costs, remained positive. However, after 2005, the number of observed cases of negative bid-ask spreads and triangular arbitrage profit opportunities became much smaller, and when they occurred, they quickly disappeared. The expected profits from arbitrage operations (attempt) became negative, when the execution risk and the transaction costs was considered.

The percentage of successful execution (fulfillment) of arbitrage orders declined sharply after 2005, while the percentage of no completion at all has increased since 2005. The percentages of partial fulfilment (only a part of a set of market-taking orders are fulfilled) has remained relatively similar before and after 2005.

The year 2005 was the first year of a large number of bank transaction computers was allowed to make a direct connection to the EBS matching supercomputer. It is highly likely that the change in transaction micro-structure can explain the disappearance of "free lunch."

The literature on negative spread and triangular arbitrage, using high-frequency data is not long. Aiba, Hatano, Takayasu, Marumo, and Shimizu (2002), examined the data for two months in 1999 detecting triangular arbitrage profit opportunities, on average for $6.4 \%$ of total time, among the yen, the dollar, and the euro. Aiba, Hatano, Takayasu, Marumo, and Shimizu (2003) and Aiba and Hatano (2004) also explored some theoretical implications of triangular arbitrage. Aiba and Hatano (2006) constructed an agent-based model for simulation. Parameters were matched to replicate the observed distribution of arbitrage profits from Aiba, et al. (2002).

The exchange rate data from an actual trading platform became available in the mid-1990s. The availability of "firm quotes," as opposed to "indicative quotes," improved the quality of research using the high-frequency exchange rate data. Goodhart, Ito and Payne (1996), Goodhart and O’Hara (1997), and Goodhart and Payne (1996) used such data, although the samples are very limited. Using the EBS data, which became available in the 2000s, Ito and Hashimoto (2006) showed the intradaily patterns. Berger et al. (2008) and Ito and Hashimoto (2008) showed that the order flows have predictable power using the reliable data. The exchange rate reactions to macroeconomic statistical announcements were analyzed in Chaboud, et al. (2008) and Hashimoto and Ito (2010). Akram and Sarno (2008) investigated arbitrage opportunities in covered interest parity relationship. Marshall, Treepongkaruna, and Young (2008) investigated triangular arbitrage opportunities involving, various advanced countries' currencies for the EBS data from January 1, 2005 to December 31, 2005. Their findings suggest triangular arbitrage opportunities arise rather frequently throughout the day. Chaboud, et al. (2010) analyzed the high-frequency volatility in the foreign exchange market.

For analysis of the execution risk, the literature is thin. Chaboud, et al. (2014) pointed out the execution risk but did not analyze it empirically. Fenn, et al. (2009) considered execution risk by defining a winning probability, and using it to calculate profit/loss of attempting taking advantage of triangular arbitrage opportunities. Their data for analysis of emergence and durability of triangular arbitrage opportunities are based on a one-week long period in the fall in each of three years, 200305 . The simulation of execution risk is conducted only for the one week (10/02/2005-10/27/2005) 
data. Engle and Ferstenberg (2007) and Engle, Ferstenberg, and Russell (2012) considered execution costs and risk from the viewpoint of portfolio management of an equity dealer who receive the customer orders and execute in the market. The data set consists of 233,913 orders executed by Morgan Stanley in 2004.

Kozhan and Tham (2012) analyzed the execution risk explicitly by modeling competition among arbitrageurs. The more competitors being active in the market, less the probability of execution. Their data come from Reuters D-3000 and EBS from January 2003 to December 04.

Foucault, Kozhan; and Tham (2017) distinguishes toxic and nontoxic arbitrage opportunities. The former is due to asynchronous adjustments in quotes following information arrival, while the latter is due to temporary price pressures. They built a model to predict that when the toxic arbitrage ratio is higher, arbitrage opportunities are shorter, even though the bid-ask spread is higher; and that a technical change allows arbitrageurs react faster, the duration of arbitrage opportunities becomes shorter. They put the theoretical predictions to test using the triangular arbitrage opportunities using the Reuters D-3000 Data set from January 2003-December 2004, with 10 millisecond frequency.

We use the USD/JPY, EUR/JPY and EUR/USD in the EBS data set that spans from 1999 to 2010, containing 1 second slice of actual deal price, deal volume and firm quotes. The following days are excluded from our samples.

(1) Weekend. From GMT 9pm. Friday to GMT 8:59pm. Sunday.

(2) End of the year to the New Years, from December 24 to January 5.

(3) Low volume of transaction. Days that had less than half of the average transaction volume of the year, where the average was calculated after exclusion of (1) and (2) are done.

In the case of triangular arbitrage, we also exclude days when regular settlement (the socalled $t+2$ ) is not possible due to national holidays. Specifically, we exclude transaction days when non-US national holidays (not including weekend) occur within two days from the transaction day; and transaction days when US national holiday falls in the second day from the transaction day.

Our paper covers much longer data compared to any of the paper cited above, and it becomes possible to link the changes in occurrence and duration of arbitrage opportunities to market microstructure. The paper also analyzes negative spread of bilateral exchange rate. We will show in this paper that the market microstructure fundamentally changed after the bank computers were allowed to connect directly to EBS matching computer, starting from 2003 and the number of connected institutions grew substantially from 2005-2010.

The rest of this paper is organized as follows. Section 2 explains the case of negative bidask spread. Section 3 the case of triangular profit opportunities. In each section, the evolution of the frequency of observing such profit opportunities from 1999 to 2010 will be described; the execution risk is defined; the profit conditional of all/partial/no fulfillment is defined and calculated; and the expected profits, taking into account execution risk and transaction costs, will be calculated. Section 4 concludes. 


\section{Negative Spread}

\subsection{Definition of negative spread}

The negative spread (NS) means that a bid quote (posted by market maker Bank B) is higher than an ask quote (posted by market maker Bank A) at time $t$, so that a third-party market-taker financial institution (Bank C) can simultaneously hit both the bid quote and the ask quote and make profits.

Let us denote the best ask quote and best bid quote for currency pair $C_{i j}=$ $\{U S D / J P Y, E U R / J P Y, E U R / U S D\}$ at time $t$ by $q a_{t}^{C_{i j}}$ and $q b_{t}^{C_{i j}}$, respectively and the case of negative spread is defined as

$$
\operatorname{Spread}_{t}^{C_{i j}}=q a_{t}^{C_{i j}}-q b_{t}^{C_{i j}}<0 .
$$

Alternatively, the above condition can be rewritten as the following condition:

$$
\frac{q b_{t}^{C_{i j}}}{q a_{t}^{C_{i j}}}>1 \text {. }
$$

\subsection{Execution Risk of Negative Bid-Ask Spread}

Conditional on the emergence of negative spread, satisfying equation (2), a market taker (Bank C)

sends two orders trying to hit both best bid, $q b_{t}^{C_{i j}}$, and the best ask, $q a_{t}^{C_{i j}}$, simultaneously. If the two orders are fulfilled, the market taker, acting as an arbitrageur, makes profit. However, there is an execution risk, that is, either one of the two orders or both may not be fulfilled, as matching at the EBS computer is done on the first-come, first-served basis to the unit of millisecond. A competitor's order may get to the EBS matching server earlier than the arbitrageur's, or the market maker withdraws the quote earlier than the arbitrageur's order reached the EBS.

We infer the execution success or failure from the bid or ask quote price movement from $t$ to $t+1$. If the bid quote is unchanged or moved higher from $t$ to $t+1$, then the arbitrageur's selling order is assumed to be fulfilled, as the price is moving even higher. Similarly, if the ask quote is unchanged or moved lower from $t$ to $t+1$, then the arbitrageur's buying order is assumed to be fulfilled, as the price is moving even lower.

When the ask or bid price moves from $t$ to $t+1$ in the direction unfavorable to the arbitrageur, then it is not certain whether the arbitrageur's order was fulfilled. We infer and assume execution success or failure as follows. The price may have moved because the arbitrageur's order hit and knocked off the best bid (or ask). Or the arbitrageur's order was not fulfilled due to competitor's have got there first to knock off the best bid (or ask), or the market maker of the best bid (or ask) have withdrawn before the arbitrageur's order got to the EBS matching engine. Hence we assign a "winning probability" for the arbitrageur's order hitting the intended bid (or ask) before the price moved. With a winning probability, $w$, the arbitrageur's order is fulfilled at price of time $t$. 
With probability of (1-w), the arbitrageur's order is not fulfilled at time $t$, but is assumed to be fulfilled at price of time $t+1$.

Thus, we can consider the following four cases, which is explained in the flow char of Figure 1.

$<$ Insert Figure 1 about here $>$

Case 11: $q b_{t}^{C_{i j}} \leq q b_{t+1}^{C_{i j}} \cap q a_{t}^{C_{i j}} \geq q a_{t+1}^{C_{i j}}$.

The arbitrage opportunity continues to exist in period $t+1$, since the bid becomes equal or higher and the ask becomes equal or lower. Hence, it is assumed that two orders to hit both bid and ask are fulfilled. The success probability of execution is one.

Case 10: $q b_{t}^{C_{i j}} \leq q b_{t+1}^{C_{i j}} \cap q a_{t}^{C_{i j}}<q a_{t+1}^{C_{i j}}$.

The bid becomes equal or higher, thus a market taker's order to hit is assumed to be fulfilled on the bid side. However, the ask becomes higher, which may be due to a successful hit by the arbitrageur or an execution failure of the arbitrageur's order. We assign the success probability, denoted by w, of the latter leg. If succeed, the arbitrageur's orders are executed at price of time $t$ on both legs. If fail, the arbitrageur's order on the ask side is fulfilled at one second later, time $t+1$, at that prevailing price.

Case 01: $q b_{t}^{C_{i j}}>q b_{t+1}^{C_{i j}} \cap q a_{t}^{C_{i j}} \geq q a_{t+1}^{C_{i j}}$.

The ask becomes equal or lower, suggesting that the arbitrageur's order is fulfilled. But, the bid becomes lower, suggesting that the arbitrageur's order being fulfilled, only with probability $w$. When fail, the order is fulfilled at time $t+1$, with the prevailing price at that time.

Case 00: $q b_{t}^{C_{i j}}>q b_{t+1}^{C_{i j}} \cap q a_{t}^{C_{i j}}<q a_{t+1}^{C_{i j}}$.

The bid becomes lower and the ask becomes higher, that is the adverse direction for the arbitrageur, in time $t+1$. It is uncertain that any of the arbitrageur's two orders are fulfilled. There are four subcases in this case: First, two legs are successfully carried out to reap NS profits in time $t$. Second, the order to hit the ask was successful at time $t$, but not on the bid side, so that hitting the bid in time $t+1$. Third, the order to hit the bid was successful at time $t$, but not on the ask side, so that hitting the ask was done in time $t+1$. Fourth, both of the arbitrageur's orders were not fulfilled.

In preparation for calculating the expected return taking into account execution risk conditional on the existence of the negative spread at time $t$, we first calculate the number and ratio 
of each case and an average return of each case for each year. First, we define the total number of seconds for each case in each sample year.

$$
T_{\text {Year }}=\{\text { all of seconds in Year }\}
$$

For example, $T_{2010}$ includes the name of seconds with negative spread, such as \{... 2010.01.21.0:00:00, 2010.01.21.00:00:01, 2010.01.21.00:00:02, ...\}.

Next, the set of seconds with negative spread is defined by $T_{\mathrm{Year}}^{\mathrm{NS}, C_{i j}}$, namely,

$$
T_{\mathrm{Year}}^{\mathrm{NS}, C_{i j}}=\left\{t \mid q b_{t}^{C_{i j}} \div q a_{t}^{C_{i j}}>1\right\} .
$$

The set of seconds that satisfies case 11 is defined as follows:

$$
T_{11, \text { Year }}^{C_{i j}}=\left\{t \mid q b_{t}^{C_{i j}} \leq q b_{t+1}^{C_{i j}} \cap q a_{t}^{C_{i j}} \geq q a_{t+1}^{C_{i j}}\right\} .
$$

Similarly, for Case 10、Case 01、Case 00, the set of seconds are defined as $T_{10 \text {,Year }}^{C_{i j}}, T_{01, \text { Year }}^{C_{i j}}, T_{00, \text { Year }}^{C_{i j}}$. The set of seconds for Case 11 conditional on negative spread (NS) is defined as follows:

$$
T_{11, \mathrm{Year}}^{\mathrm{NS}, C_{i j}}=T_{\mathrm{Year}}^{\mathrm{NS}, C_{i j}} \cap T_{11, \mathrm{Year}}^{C_{i j}}
$$

The probability of Case 11, given NS is calculated as follows:

$$
p_{11, \text { Year }}^{\mathrm{NS}, C_{i j}}=n_{11, \mathrm{Year}}^{\mathrm{NS}, C_{i j}} / n_{\mathrm{Year}}^{\mathrm{NS}, C_{i j}},
$$

where

$$
n_{\text {Year }}^{\mathrm{NS}, C_{i j}}=\# T_{\mathrm{Year}}^{\mathrm{NS}, C_{i j}}, n_{11, Y e a r}^{N S, C_{i j}}=\# T_{11, \text { Year }}^{N S, C_{i j}} .
$$

And '\#' denotes the number of elements in the set.

Table 1 shows the total number of seconds and the ratio of Cases 11, 10, 01,00 for the each of the currency pair $C_{i j}=\{\mathrm{USD} / \mathrm{JPY}, \mathrm{EUR} / \mathrm{USD}, \mathrm{EUR} / \mathrm{JPY}\}$ for each sample year.

$$
<\text { Insert Table } 1 \text { about here }>
$$

\section{Expected return of sending orders to hit NS quotes}

When the arbitrageur detects the profit opportunities of negative spread, he/she/it would like to send orders in an attempt to reap the profit. However, the arbitrageur is mindful of an execution risk, that is, (part of) the orders may not be fulfilled. Therefore, orders are sent only when the expected profit is positive. In order to calculate the expected profit, profits of each of the four cases in the flow chart of Figure 1 has to be calculated first and then the weighted average has to be calculated. 
The return in each case is calculated as follows. The return for Case 00 is zero by definition. The return for Case 11 is positive (or more than 1 in the defined ratio) by definition. The return of case 11 is calculated as follows:

$$
r_{11, \text { Year }}^{\mathrm{NS}, C_{i j}}=\frac{1}{n_{11, \text { Year }}^{\mathrm{NS}, C_{i j}}} \sum_{\substack{\mathrm{NS}, C_{i j} \\ t \in T_{11, \mathrm{Year}}}}\left(q b_{t}^{C_{i j}} \div q a_{t}^{C_{i j}}\right) .
$$

The returns for Cases 01 and 10 are similarly defined. Case00 does not involve the transaction so that $r_{00, \text { Year }}^{\mathrm{NS}, C_{i j}}=1$. Table 2 shows the average (over the year) return for each of the execution cases $\{11$, 01, and 10 \}, for each of sample years. Case 11 means both of the two legs of orders to exploit NS are executed so that the profit was positive $(r>1)$. Returns in Cases 01 and 10 are negative $(r<1)$.

\section{$<$ Insert Table 2 about here $>$}

The arbitrageur when he/she/it detects the existence of NS calculates the average return of sending orders for execution, taking into account which case $(11,01,10$, or 00$)$ it may end up and expected returns (average of the year) for each case. ${ }^{1}$ Equation (9) shows the average return of sending orders for execution upon an observation of NS, using the probabilities of Cases of execution, $p_{i j, \text { Year }}^{\mathrm{NS}, C_{i j}}$ (Table 1) and returns of each Case $r_{i j, \text { Year }}^{\mathrm{NS}, C_{i j}}$ (Table 2).

Each executed trade is charged with the EBS transaction fee, which is denoted by $c$, and in case of 01 or 10, the winning order ratio, $w$, is introduced. With probability of $w$, the arbitrageur's order is executed at the price at $t$, before price moves unfavorably to the arbitrageur. The winning ratio means a ratio to beat competitor in the race to the EBS matching computer, or quick enough to hit it before the original market maker withdraws the best price at time $t$. Each component of the expected profits is the profits conditional on each Case, multiplied by the probability of the case (average seconds in the case among the total NS time) and the winning probability (simulation parameter) and the not-winning probability in Cases of 01, 10 and 00.

$$
\begin{aligned}
& r_{\mathrm{Year}}^{\mathrm{NS}, \mathrm{USD} / \mathrm{JPY}}=\left(r_{11, \mathrm{Year}}^{\mathrm{NS}, \mathrm{USD} / \mathrm{JPY}}-c\right) \times p_{11, \mathrm{Year}}^{\mathrm{NS}, \mathrm{JPY}} \\
& +\left(r_{11, \text { Year }}^{\mathrm{NS}, \mathrm{USD}}-c\right) \times p_{01, \mathrm{Year}}^{\mathrm{NS}, \mathrm{USD} / \mathrm{JPY}} \times W^{+}\left(r_{01, \mathrm{Year}}^{\mathrm{NS}, \mathrm{JPY}}-c\right) \times p_{01, \mathrm{Year}}^{\mathrm{NS}, \mathrm{USD} / \mathrm{JPY}} \times\left(1-{ }^{\prime}\right) \\
& +\left(r_{11, \mathrm{Year}}^{\mathrm{NS}, \mathrm{USP}}-c\right) \times p_{10, \mathrm{Year}}^{\mathrm{NS}, \mathrm{USD} / \mathrm{JPY}} \times W+\left(r_{10, \mathrm{Year}}^{\mathrm{NS}, \mathrm{USD} / \mathrm{JPY}}-c\right) \times p_{10, \mathrm{Year}}^{\mathrm{NS}, \mathrm{USD} / \mathrm{JPY}} \times(1-w)
\end{aligned}
$$

\footnotetext{
1 Here and in the rest of this paper, the arbitrageur is assumed to be risk neutral, so that the average return for each case in each year is sufficient to consider for the order decision.
} 


$$
\begin{aligned}
& +\left(r_{11, \mathrm{Year}}^{\mathrm{NS}, \mathrm{USD} / \mathrm{JPY}}-c\right) \times p_{00, \mathrm{Year}}^{\mathrm{NS}, \mathrm{USD} / \mathrm{JPY}} \times w^{2} 1+\left(r_{10, \mathrm{Y} \text { Year }}^{\mathrm{NS}, \mathrm{USD} / \mathrm{JPY}}-c\right) \times p_{00, \mathrm{Year}}^{\mathrm{NS}, \mathrm{USD} / \mathrm{JPY}} \times w(1-w) \\
& +\left(r_{01, \mathrm{Year}}^{\mathrm{NS}, \mathrm{USD} / \mathrm{JPY}}-c\right) \times p_{00, \mathrm{Year}}^{\mathrm{NS}, \mathrm{USD} / \mathrm{JPY}} \times w(1-w)+1 \times p_{00, \mathrm{Year}}^{\mathrm{NS}, \mathrm{USD} / \mathrm{JPY}} \times(1-w)^{2}
\end{aligned}
$$

The log (base 10) return is defined as follows:

$$
\mu_{\mathrm{Year}}^{\mathrm{NS}, \mathrm{USD} / \mathrm{JPY}}=\log _{10}\left(r_{\mathrm{Year}}^{\mathrm{NS}, \mathrm{USD} / \mathrm{JPY}}\right) .
$$

Figure 2 shows the matrix of expected returns, in equation (10), as a function of the winning ratio (horizontal row) for each year (vertical column). The execution fee is assumed to be $\$ 6$ per contract (\$1 million). ${ }^{2}$ Fig. 2 is a heat map where the darker cell implies more profitable and the lighter cell implies a loss. If the winning probability is higher, the average return is higher. The average profits became smaller and sometimes turns a loss as the year passes by, given the winning probability.

$<$ Insert Figure 2 about here $>$

The direct connection of bank computers to the EBS matching engine started on the limited scale in 2003 and the number of connection gradually increased to 2010. The algorithmic program can easily detect the emergence of negative spread (NS) and react to it much faster than humans. Until 2002, even in the case of the winning probability of 0 , the profit was expected until 2002. When the NS is detected the market maker with quick fingers should (and probably did) send order for execution, and made profits. More recently, after 2005, the arbitrageur faces the expected loss, thus should not send execution orders even detecting NS at period $t$. However, if your algorithm is much faster than others, namely the winning probability is higher, there could be still expected profits.

Figures 3 and 4 show the expected returns, net of transaction costs and taking into account of execution risk, for the currency pairs of EUR/USD and EUR/JPY, respectively. Similar to Figures 1 and 2 , the expected return is a function of winning probabilities in cases of 01 and 10 . The horizontal axis is the year. The gain/loss table of the EUR/USD shows a result similar to the USD/JPY. Namely, the prior to 2003, regardless of the winning probability, the expected profit of sending two orders was positive, conditional on the detection of a triangular arbitrage opportunity. The winning probability became to matter after 2003 more and more. By 2006, winning probability exceeding 70 percent was required to make the expected profit positive.

$<$ Insert Figures 3 and 4 here>

2 The fee is based on our interview to EBS. This is close to what EBS charges to large volume customers. 
The EUR/JPY shows much lower expected return in executing an arbitrage opportunity. Even before bank machines became directly connected to the EBS computer, higher winning ratios, typically higher than $40 \%$ were required to command a positive profit in attempting execution. The EUR/JPY market was not very liquid in the first half of the 1990s. The bid-ask spread was wider than other two currency pairs. When one of the two legs of transaction fail to be executed, the exchange rate of actual execution one second later was much worse in terms of arbitrage opportunity.

\section{Triangular Arbitrage}

\subsection{Definition: Triangular Arbitrage}

The triangular arbitrage opportunities can be understood as profits from a set of three simultaneous transactions: (Eastward) Selling the yen (JPY) to buy the US dollar (USD); selling the USD to buy the euro (EUR); and finally selling EUR to buy JPY; or (Westward) Selling JPY to buy EUR; selling EUR to buy USD; and selling USD to buy JPY. The words, Eastward and Westward are used to make it easier to understood, but the transactions are time-wise simultaneous executed and geographically in any market. Since a set of transactions has to be executed simultaneously, the original currency for an explanation purpose is irrelevant in calculation of profits.

In either Eastward or Westward transactions, if the amount of Yen after three transactions is more than that of yen before the three transactions, it is defined that there is a profit opportunity of triangular arbitrage. Let us follow the precise definition, provided in Ito et al. (2012). The three currency pairs are said to have a positive (normal) bid-ask spread, when:

For USD/JPY: $q a_{t}^{\mathrm{USD} / \mathrm{JPY}}>q b_{t}^{\mathrm{USD} / \mathrm{JPY}}$, with mid-point of $q m_{t}^{\mathrm{USD} / \mathrm{JPY}}$

For EUR/USD: $q a_{t}^{\mathrm{EUR} / \mathrm{USD}}>q b_{t}^{\mathrm{EUR} / \mathrm{USD}}$, with mid-point of $q m_{t}^{\mathrm{EUR} / \mathrm{USD}}$

For EUR/JPY: $q a_{t}^{\mathrm{EUR} / \mathrm{JPY}}>q b_{t}^{\mathrm{EUR} / \mathrm{JPY}}$, with mid-point of $q m_{t}^{\mathrm{EUR} / \mathrm{JPY}}$

Even when all the three positive bid-ask spread conditions are satisfied, a possibility of arbitrage profits may exist by combining simultaneous transactions of three currency pairs. Suppose a series of transaction that takes the yen to the US dollar, to Euro, and back to the yen. First the buying the US dollar takes at the ask side (quoted price of USD seller); then buying the euro with the US dollar takes place at the ask side (quoted price of Euro seller); and finally exchanging the euro back to the yen should be on the bid side of the EUR/JPY. Thus, profits from the triangular arbitrage, TA, considering the bid-ask, in the three Eastward transactions of JPY $\rightarrow$ USD $\rightarrow$ EUR $\rightarrow$ JPY is defined as

$$
\mathrm{TA}(\mathrm{JPY} / \mathrm{USD} / \mathrm{EUR} / \mathrm{JPY})=T A^{E}=\frac{1}{q a_{t}^{\mathrm{USD} / \mathrm{JPY}}} \times \frac{1}{q a_{t}^{\mathrm{EUR} / \mathrm{USD}}} \times q b_{t}^{\mathrm{EUR} / \mathrm{JPY}}
$$

Similarly, the amount of yen after the three Westward transactions of JPY $\rightarrow$ EUR $\rightarrow$ USD $\rightarrow$ JPY is denoted as follows: 


$$
\mathrm{TA}(\mathrm{JPY} / \mathrm{EUR} / \mathrm{USD} / \mathrm{JPY})=T A^{W}=\frac{1}{q a_{t}^{\mathrm{EUR} / \mathrm{JPY}}} \times q b_{t}^{\mathrm{EUR} / \mathrm{USD}} \times q b_{t}^{\mathrm{USD} / \mathrm{JPY}}
$$

\subsection{Execution Risk of Triangular Arbitrage}

This subsection examines profitability of triangular arbitrage, taking into account transaction costs and execution risk. As in the case of negative spread, we infer a success in execution from change/no change in best bid and best ask quotes in one second after an arbitrage opportunity arises. When a quote moves in an adverse direction, we examine a success probability in execution. A triangular arbitrage involves three legs of transactions to complete an arbitrage strategy. If only one or two initial orders are completed, the arbitrageur has to decide to carry out the remaining trades, one second later with adverse prices, or to unwind the partially buildup positions. The expected profit/loss on the recovery tactics will be calculated.

Triangular arbitrages involving Yen, Dollar and Euro, has a two types: One exchanges currencies from JPY to USD, USD to EUR, and EUR to JPY; and another from JPY to EUR; EUR to USD, and USD to JPY. Since all orders are placed simultaneously, the sequence does not matter. Technically the two strategies differ in whether bid or ask is used in each currency.

Figures 5 and 6 show the flow charts of execution possibilities when the three orders to exploit an triangular arbitrage are placed. Figure 5 shows the case of JPY to USD, to EUR and to JPY; while Figure 6 shows the case of JPY to EUR, to USD, and to JPY. Again the order of executions is irrelevant to the layer of flow chart can be flipped. In each case, the execution possibility is categorized in eight cases: $\{111,110,101,011,100,010,001,000\}$. When the index is 1 , the order is executed at time $t$; and when the index is 0 , then with probability $w$, the order is executed at time $t$, and with probability (1-w), the order is executed at time $(t+1)$. This is explicitly explained the case that includes 0 once, but it is implicit in the case that includes 0 twice or three times, in order to save space.

\section{$<$ Insert Figures 5 and 6 about here $>$}

First, the frequencies, probability of emergences, and average returns of each of eight cases will be calculated. For each calendar year, the set of time (in seconds) in that Eastward triangular arbitrage (JPY-USD-EUR-JPY) opportunities are present is defined as follows:

$$
T_{\text {Year }}^{\mathrm{TA}-E}=\left\{t \mid T A_{t}^{E}>1.00001, \frac{q b_{t}^{\mathrm{USD} / J P Y}}{q a_{t}^{\mathrm{USD} / \mathrm{PY}}}<1, \frac{q b_{t}^{\mathrm{EUR} / \mathrm{USD}}}{q a_{t}^{\mathrm{EUR} / \mathrm{USD}}}<1, \frac{q b_{t}^{\mathrm{EUR} / \mathrm{JPY}}}{q a_{t}^{\mathrm{EUR} / \mathrm{JPY}}}<1\right\}
$$

where

$$
q b_{t}^{\mathrm{USD} / \mathrm{JPY}} / q a_{t}^{\mathrm{USD} / \mathrm{JPY}}<1, q b_{t}^{\mathrm{EUR} / \mathrm{USD}} / q a_{t}^{\mathrm{EUR} / \mathrm{USD}}<1, q b_{t}^{\mathrm{EUR} / \mathrm{JPY}} / q a_{t}^{\mathrm{EUR} / \mathrm{JPY}}<1
$$

means that each currency pair is not showing negative spread. Similarly the set of time (in seconds) in that Westward triangular arbitrage (JPY-EUR-USD -JPY) opportunities are present is defined as follows:

$$
T_{\text {Year }}^{\mathrm{TA}-W}=\left\{t \mid \mathrm{TA}_{t}^{W}>1.00001, \frac{q b_{t}^{\mathrm{USD} / \mathrm{JPY}}}{q a_{t}^{\mathrm{USD} / \mathrm{PY}}}<1, \frac{q b_{t}^{\mathrm{EUR} / \mathrm{USD}}}{q a_{t}^{\mathrm{EUR} / \mathrm{USD}}}<1, \frac{q b_{t}^{\mathrm{EUR} / \mathrm{JPY}}}{q a_{t}^{\mathrm{EUR} / \mathrm{JPY}}}<1\right\}
$$


The set of time (in seconds), i.e., cumulative seconds, for Case $\{111\}$, whether or not it represent triangular opportunities, in Figure 5 (Eastward transactions) is defined as follows:

$$
T_{111, \mathrm{Year}}^{\mathrm{E}}=\left\{t \mid q a_{t}^{\mathrm{USD} / J \mathrm{PY}} \geq q a_{t}^{\mathrm{USD} / J \mathrm{PY}}, q a_{t}^{\mathrm{EUR} / \mathrm{USD}} \geq q a_{t}^{\mathrm{EUR} / \mathrm{USD}}, q b_{t}^{\mathrm{EUR} / \mathrm{JPY}} \leq q b_{t}^{\mathrm{EUR} / \mathrm{JPY}}\right\}
$$

Hence, the set of time, in which trilateral arbitrage of (JPY-USD-EUR-JPY) is present and in Case $\{111\}$, is defined as the intersection of two sets:

$$
T_{111, \text { Year }}^{\mathrm{TA}}=T_{\text {Year }}^{\mathrm{TA}-\mathrm{E}} \cap T_{111, \text { Year }}^{\mathrm{E}}
$$

Similarly, the set of time for each of cases $\{110\},\{101\},\{011\},\{100\},\{010\},\{001\}$ and $\{000\}$ is defined. In parallel, sets are defined in the triangular arbitrage of the reverse direction: JPY-EURUSD-JPY.

The number of seconds, $n$, in a year for Eastward triangular arbitrage opportunity case is defined as:

$$
n_{\text {Year }}^{\mathrm{TA}-\mathrm{E}}=\# T_{\text {Year }}^{\mathrm{TA}-\mathrm{E}}
$$

And similarly for the Westward one as:

$$
n_{\text {Year }}^{T A-W}=\# T_{\text {Year }}^{T A-W}
$$

The number of seconds for Case 111 for East and West triangular arbitrage opportunities is, respectively, defined as:

$$
\begin{aligned}
& n_{111, \mathrm{Year}}^{\mathrm{TA}-\mathrm{E}}=\# T_{111, \mathrm{Year}}^{\mathrm{TA}-\mathrm{E}} \\
& n_{111, \mathrm{Year}}^{\mathrm{TA}-\mathrm{W}}=\# T_{111, \mathrm{Year}}^{\mathrm{TA}-\mathrm{W}}
\end{aligned}
$$

Hence, given arbitrage opportunities being present, the probability of Case $\{111\}$, for Eastward and Westward, respectively, is calculates as:

$$
\begin{aligned}
& p_{111, \mathrm{Year}}^{T A-E}=n_{111, \mathrm{Year}}^{T A-E} / n_{\text {Year }}^{T A-E} \\
& p_{111, \text { Year }}^{T A-W}=n_{111, \text { Year }}^{T A-W} / n_{\text {Year }}^{T A-W}
\end{aligned}
$$

Tables 3E and 3W show the time series (annual) changes of the number of occurrence, the probability of occurrence for each of the sample years, for Eastward and Westward, respectively. The probability of case $\{111\}$ declined over the year, and the probabilities of other cases have increased instead. Similarly, the number and probability (ratio) for each Case $\{x, y, z\}$, where $x=\{0$, $1\} ; y=\{0,1\}$; and $z=\{0,1\}$, is calculated.

$<$ Insert Tables 3E and 3W about here $>$ 
Next, we calculate the return for each of the Cases $\{x, y, z\}$. In case of Case 111, the return for Eastward triangular arbitrage and Westward triangular arbitrage are calculated as follows:

$$
\begin{aligned}
& r_{111, \text { Year }}^{T A-E}=\frac{1}{n_{111, \text { Year }}^{T A}}\left\{\sum_{t \in T_{111, \text { Year }}^{T A-E}} T A^{E}(t)\right\} \\
& r_{111, \text { Year }}^{T A-W}=\frac{1}{n_{111, \text { Year }}^{T A}}\left\{\sum_{t \in T_{111, Y}^{T A-W}} T A^{W}(t)\right\}
\end{aligned}
$$

Similarly, Case110,101,011,100,010,001,000 are defined and calculated. Tables 4E and 4W show an annual average return from 1999 to 2010. Returns in Case111 always exceeds 1, that is, profits are realized, since conditions suggest successful execution. Other cases $\{110,101,011,100,010,001$, $000\}$, indicating at least one of the three leg transactions fail to materialize and the price moves in an adverse direction, are calculated with possible losses.

$<$ Insert Tables 4E and 4W about here>

\subsection{Profitability}

Using probabilities of cases $\{111,110,101,011,100,010,001,000\}$ in Table $3, p_{x y z, Y e a r}^{T A}$, and average returns of cases of $\{111,110,101,011,100,010,001\}$ in Table $4, r_{x y z, \text { Year }}^{\text {TA }}$, we can calculate the executable average returns, given the triangular arbitrage opportunities being detected, for each year, as shown in equation (18) below. Here, $c$ and $w$ denote the commission fee (paid to EBS) and the probability of successful execution (winning) when the price moves in an adverse direction one second later.

$$
\begin{aligned}
& r_{\mathrm{Year}}^{\mathrm{TA}}=\left(r_{111, \text { Year }}^{\mathrm{TA}}-c\right) \times p_{111, \text { Year }}^{\mathrm{TA}} \\
& +\left(r_{111, \text { Year }}^{\mathrm{TA}}-c\right) \times p_{110, \text { Year }}^{\mathrm{TA}} \times w+\left(r_{110, \text { Year }}^{\mathrm{TA}}-c\right) \times p_{110 \text {,Year }}^{\mathrm{TA}} \times(1-w) \\
& +\left(r_{111, \text { Year }}^{\mathrm{TA}}-c\right) \times p_{101, \text { Year }}^{\mathrm{TA}} \times w+\left(r_{101, \text { Year }}^{\mathrm{TA}}-c\right) \times p_{101, \text { Year }}^{\mathrm{TA}} \times(1-w) \\
& +\left(r_{111, \text { Year }}^{\mathrm{TA}}-c\right) \times p_{011, \text { Year }}^{\mathrm{TA}} \times w+\left(r_{011, \text { Year }}^{\mathrm{TA}}-c\right) \times p_{011, \text { Year }}^{\mathrm{TA}} \times(1-w) \\
& +\left(r_{111, \text { Year }}^{\mathrm{TA}}-c\right) \times p_{100, \text { Year }}^{\mathrm{TA}} \times w+\left(r_{110, \text { Year }}^{\mathrm{TA}}-c\right) \times p_{100, \text { Year }}^{\mathrm{TA}} \times(1-w) \\
& +\left(r_{111, \text { Year }}^{\mathrm{TA}}-c\right) \times p_{100, \text { Year }}^{\mathrm{TA}} \times w^{2}+\left(r_{110, \text { Year }}^{\mathrm{TA}}-c\right) \times p_{100, \text { Year }}^{\mathrm{TA}} \times w(1-w) \\
& +\left(r_{101, \text { Year }}^{\mathrm{TA}}-c\right) \times p_{100, \text { Year }}^{\mathrm{TA}} \times w(1-w)+\left(r_{100, \text { Year }}^{\mathrm{TA}}-c\right) \times p_{100, \text { Year }}^{\mathrm{TA}} \times(1-w)^{2} \\
& +\left(r_{111, \text { Year }}^{\mathrm{TA}}-c\right) \times p_{010, \text { Year }}^{\mathrm{TA}} \times w^{2}+\left(r_{110, \text { Year }}^{\mathrm{TA}}-c\right) \times p_{010, \text { Year }}^{\mathrm{TA}} \times w(1-w) \\
& +\left(r_{011, \text { Year }}^{\mathrm{TA}}-c\right) \times p_{010, \mathrm{Year}}^{\mathrm{TA}} \times w(1-w)+\left(r_{010, \mathrm{Year}}^{\mathrm{TA}}-c\right) \times p_{010, \mathrm{Year}}^{\mathrm{TA}} \times(1-w)^{2} \\
& +\left(r_{111, \text { Year }}^{\mathrm{TA}}-c\right) \times p_{001, \text { Year }}^{\mathrm{TA}} \times w^{2}+\left(r_{101, \text { Year }}^{\mathrm{TA}}-c\right) \times p_{001, \text { Year }}^{\mathrm{TA}} \times w(1-w) \\
& +\left(r_{011, \mathrm{Year}}^{\mathrm{TA}}-c\right) \times p_{001, \mathrm{Year}}^{\mathrm{TA}} \times w(1-w)+\left(r_{001, \mathrm{Year}}^{\mathrm{TA}}-c\right) \times p_{001, \mathrm{Year}}^{\mathrm{TA}} \times(1-w)^{2} \\
& +\left(r_{111, \text { Year }}^{\mathrm{TA}}-c\right) \times p_{000, \text { Year }}^{\mathrm{TA}} \times w^{3}+\left(r_{110, \mathrm{Year}}^{\mathrm{TA}}-c\right) \times p_{000, \mathrm{Year}}^{\mathrm{TA}} \times w^{2}(1-w) \\
& +\left(r_{101, \text { Year }}^{\mathrm{TA}}-c\right) \times p_{000, \text { Year }}^{\mathrm{TA}} \times w^{2}(1-w)+\left(r_{011, \text { Year }}^{\mathrm{TA}}-c\right) \times p_{000, \text { Year }}^{\mathrm{TA}} \times w^{2}(1-w)
\end{aligned}
$$




$$
\begin{aligned}
& +\left(r_{100, \text { Year }}^{\mathrm{TA}}-c\right) \times p_{000, \text { Year }}^{\mathrm{TA}} \times w(1-w)^{2}+\left(r_{010, \text { Year }}^{\mathrm{TA}}-c\right) \times p_{000, \mathrm{Year}}^{\mathrm{TA}} \times w(1-w)^{2} \\
& +\left(r_{001, \text { Year }}^{\mathrm{TA}}-c\right) \times p_{000, \text { Year }}^{\mathrm{TA}} \times w(1-w)^{2}+1 \times p_{000, \text { Year }}^{\mathrm{TA}} \times(1-w)^{3}
\end{aligned}
$$

The log returns (with base of 10) of equation (18) are defined as follows:

$$
\mu_{\text {Year }}^{\mathrm{TA}}=\log _{10}\left(r_{\text {Year }}^{\mathrm{TA}}\right) \text {. }
$$

Figures 7E and 7W shows the average log-returns depending on the $w$ parameter moving from 0 to 1 by unit of 0.1 for each year from 1999 to 2010, depending on the eastward arbitrage (JPY - USD EUR - JPY) and the westward arbitrage (JPY - EUR - USD - JPY), respectively. The commission

fee is assumed to be $c=9 \times 10^{-6}$. Hence Figures 7E and 7W show average returns of triangular arbitrage with execution risk and transaction cost $\left(\mu_{\text {Year }}^{T A}\right)$.

The winning probability has to be much higher to make triangular arbitrage opportunities profitable with execution risk, compared to cases of negative spreads. This is sensible because taking advantage of a triangular arbitrage opportunity requires three transactions that are exposed to execution risk, while two transactions to negative spread. It is also obvious that even higher winning probabilities are required to generate profits when algorithm trading became prevalent after 2003.

\section{Concluding Remarks}

This paper examined one-second slice of high-frequency data from 1999 to 2010. With the highfrequency data of firm quotes in the transaction platform of foreign exchanges, arbitrage profit opportunities - in the forms of a negative bid-ask spread of a currency pair and triangular transactions involving three currency pairs — can be detected to emerge and disappear in the matter of seconds. The frequency and duration of such arbitrage opportunities have declined over time, and almost disappeared by the mid-2000s. The declining frequency of appearance and shortening duration of arbitrage opportunities can be attributable to the proliferation of algorithm trading and other innovations in the market. Critics of the existence of such "free lunch" opportunities would argue that opportunities are not exploitable once the transactions costs and execution risk are taken into account. In this paper, we will show that profits remain positive even after transactions costa and executions were possible most of the time. When a human trader detects such an arbitrage opportunity and places orders for multiple transactions - two in negative spreads and three in triangular arbitrage - there is no guarantee all of those orders are fulfilled in a fraction of one second. Thus, the arbitrageur has to consider execution risk, when he/she/it detects the emergence of such an opportunity.

Execution risk as well as transaction costs was explicitly considered in calculation of profits, by examining a change in the best ask and bid from one second to next for each emergence of the 
arbitrage opportunity. We calculated the expected profits depending on some parameters, tie-brake rule for competing orders, on execution risk.

The novelty of this paper is to show that those arbitrage opportunities were exploitable and executable, before 2004, even considering the transactions costs and execution risk. After many algorithmic computers were allowed to be connected directly to the transaction platform in 2005, the frequency of free lunch cases has declined and probabilities of successful executions of all legs for arbitrage declined. We calculate the change in the expected profit of an attempt to execute necessary transactions to reap benefits from arbitrage opportunity. 


\section{References}

Aiba, Yukihiro and Naomichi Hatano (2004). "Triangular Arbitrage in the Foreign Exchange Market,” Physica A 344, 2004, 174-177.

Aiba, Yukihiro and Naomichi Hatano (2006). “A microscopic model of triangular arbitrage” Physica A 371, 2006, 572-584.

Aiba, Yukihiro; Naomichi Hatano; Hideki Takayasu; Kouhei Marumo; and Tokiko Shimizu (2002). “Triangular arbitrage as an interaction among Foreign exchange rates,” Physica A 310, 2002, 467479.

Aiba, Yukihiro; Naomichi Hatano; Hideki Takayasu; Kouhei Marumo; and Tokiko Shimizu (2003). “Triangular arbitrage and Negative Auto-correlation of Foreign Exchange Rates,” Physica A 314, 2003, 253-257.

Akram, Farooq and Lucio Sarno (2008). "Arbitrage in the Foreign Exchange Market: Turning on the Microscope,” Journal of International Economics, vol. 76, 2008, 237-253.

Berger, David W., Alain P. Chaboud, Sergey V. Chernenko, Edward Howorka, and Jonathan H. Wright (2008). "Order Flow and Exchange Rate Dynamics in Electronic Brokerage System Data," Journal of International Economics, vol. 75, no. 1, 2008, 93-109.

Chaboud, Alain P., Sergey V. Chernenko, and Jonathan H. Wright (2008). "Trading Activity and Macroeconomic Announcements in High-Frequency Exchange Rate Data," Journal of the European Economic Association, vol. 6, no. 2-3, 589-596.

Chaboud, Alain P., Benjamin Chiquoine, Erik Hjalmarsson, and Mico Loretan (2010). "Frequency of Observation and the Estimation of Integrated Volatility in Deep and Liquid Financial Markets," Journal of Empirical Finance, vol. 17, no. 2, 212-240.

Chaboud, Alain, Benjamin Chiquoine, Erik Hjalmarsson, and Clara Vega (2014). "Rise of the Machines: Algorithmic Trading in the Foreign Exchange Market," Journal of Finance, vol. 69, no. 5, 2045-2084.

Engle, Robert and Robert Ferstenberg (2007). "Execution Risk,” Journal of Portfolio Management, vol. 33, no. 2, 34-45. 
Engle, Robert; Robert Ferstenberg, and Jeffrey Russell (2012). "Measuring and Modeling Execution Cost and Risk,” Journal of Portfolio Management, Winter vol. 38, no. 2: 14-28.

Fenn, Daniel J.; Sam D. Howison; Mark McDonald; Stacy Williams; and Neil F. Johnson, (2009). “The mirage of triangular arbitrage in the spot foreign exchange market” International Journal of Theoretical and Applied Finance Volume 12, Issue 8, December 2009: 1105-1123.

Foucault, Thierry; Roman Kozhan; and WingWah Tham, (2017). “Toxic Arbitrage,” Review of Financial Studies, vol. 30, no. 4: 1053-1094.

Goodhart, Charles, Ito, Takatoshi, and Payne, Richard (1996). “One day in June 1993: a study of the working of the reuters 2000-2 electronic foreign exchange trading system,” in Frankel, J.A., Galli, G., Giovannini, A. (Eds.), The Microstructure of Foreign Exchange Markets. The University of Chicago Press, Chicago, 107-179.

Goodhart, C.A.E. and O’Hara, M. (1997). "High frequency data in financial markets: Issues and applications.” Journal of Empirical Finance, 4, 73-114.

Goodhart, Charles, Payne, Richard (1996). "Microstructural dynamics in a foreign exchange electronic broking system,” Journal of International Money and Finance 15 (6), 829-85.

Hashimoto, Yuko and Takatoshi Ito (2010). “Effects of Japanese Macroeconomic Announcements on the Dollar/Yen Exchange Rate: High-Resolution Picture,” Journal of the Japanese and International Economies vol. 24, 334-354.

Ito, Takatoshi and Yuko Hashimoto (2006). "Intra-day Seasonality in Activities of the Foreign Exchange Markets: Evidence from the Electronic Broking System” Journal of the Japanese and International Economies, vol. 20, no. 4, 637-664.

Ito, Takatoshi and Yuko Hashimoto (2008). "Price Impacts of Deals and Predictability of the Exchange Rate Movements,” in T. Ito and A. Rose (eds.), International Financial Issues in the Pacific Rim, NBER East Asia Seminar on Economics, Volume 17, Chicago: University of Chicago Press, 177-215.

Ito, Takatoshi; Kenta Yamada; Misako Takayasu; and Hideki Takayasu (2012), Free Lunch! Arbitrage Opportunities in the Foreign Exchange Markets” NBER Working Paper No. 18541, November. 
Kozhan, R. and Tham, W. W. (2012). "Execution risk in high-frequency arbitrage," Management Science, Volume 58, Number 11, 2131-2149.

Marshall, Ben R., Treepongkaruna, Sirimon and Young, Martin R. (2010). "What Level of Compensation is Available to Arbitrageurs in the Foreign Exchange Market?” AFA 2008 New Orleans Meetings Paper. http://ssrn.com/abstract=970410 
Figures

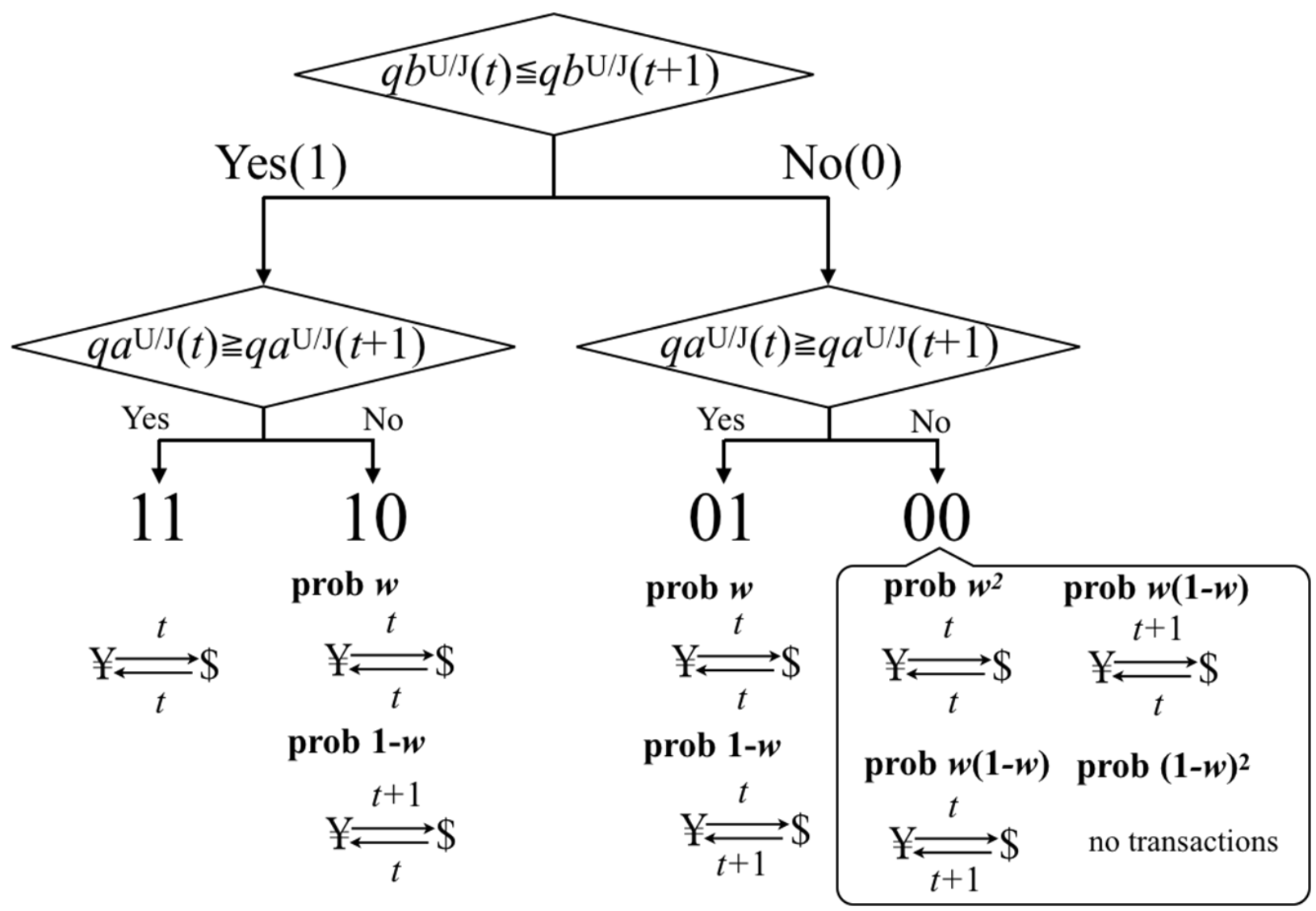

Figure 1 Flow chart of success and failure of arbitrageur's orders for execution 


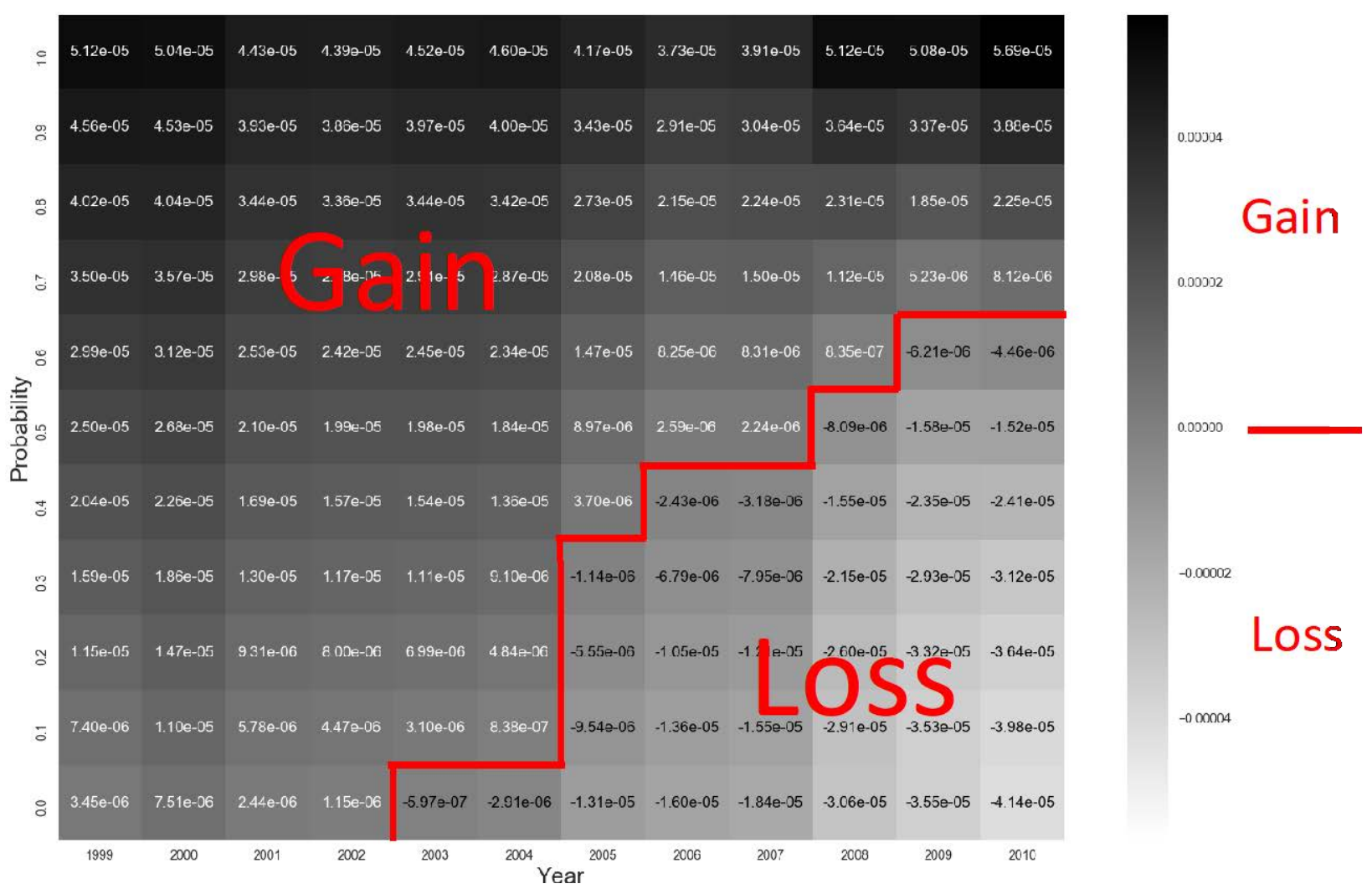

Figure 2 The average returns of sending orders of execution conditional of NS: $\left(\mu_{\text {Year }}^{\mathrm{NSS} \text { USP }}{ }^{\mathrm{JPY}}\right)$. Notes: The Horizontal axis is year; and the vertical axis is the winning probability. 


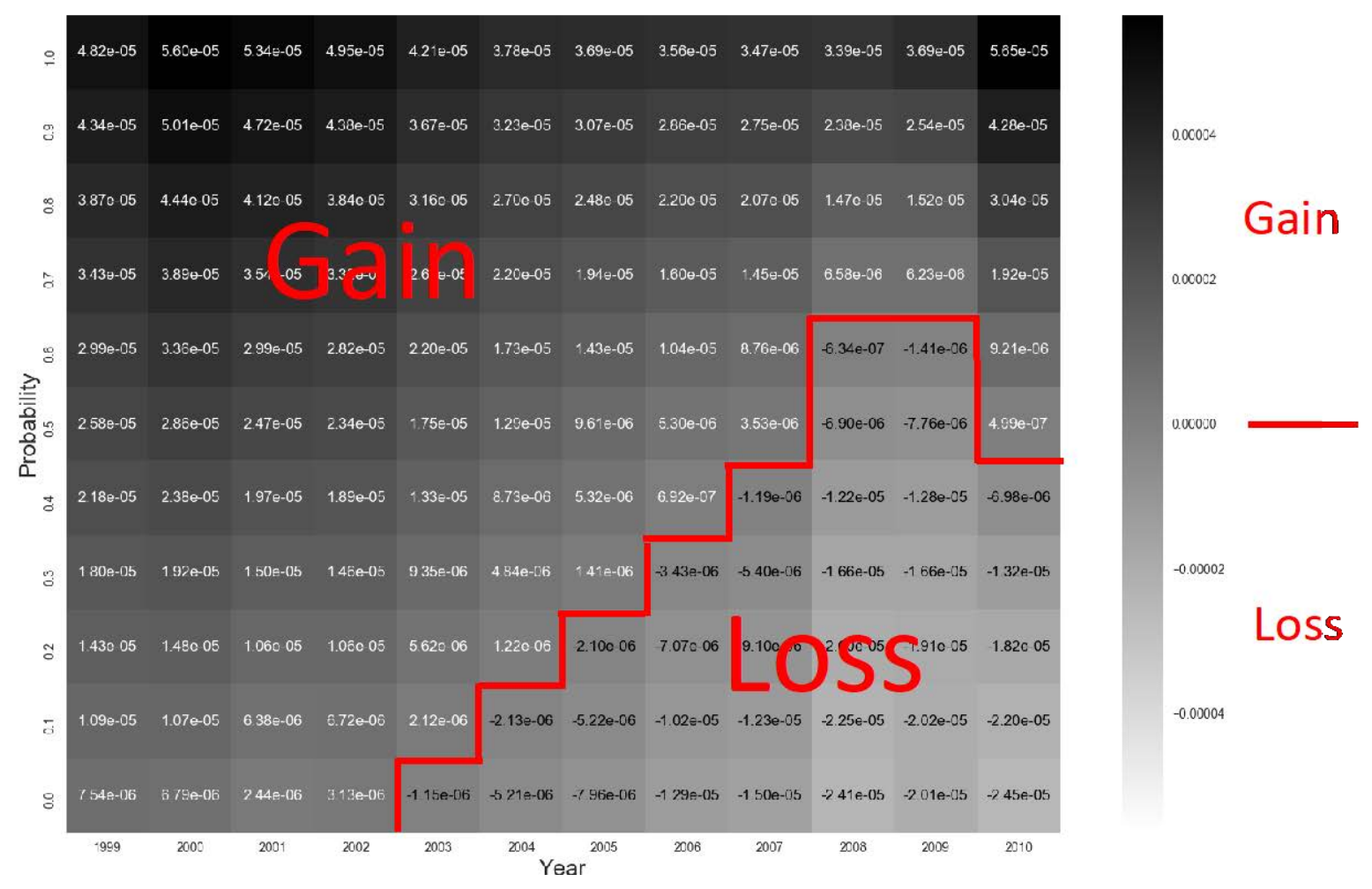

Figure 3 Expected returns for the currency pair of EUR/USD: $\left(\mu_{\mathrm{Year}}^{\mathrm{NS} \text { EUR/USD }}\right)$ 


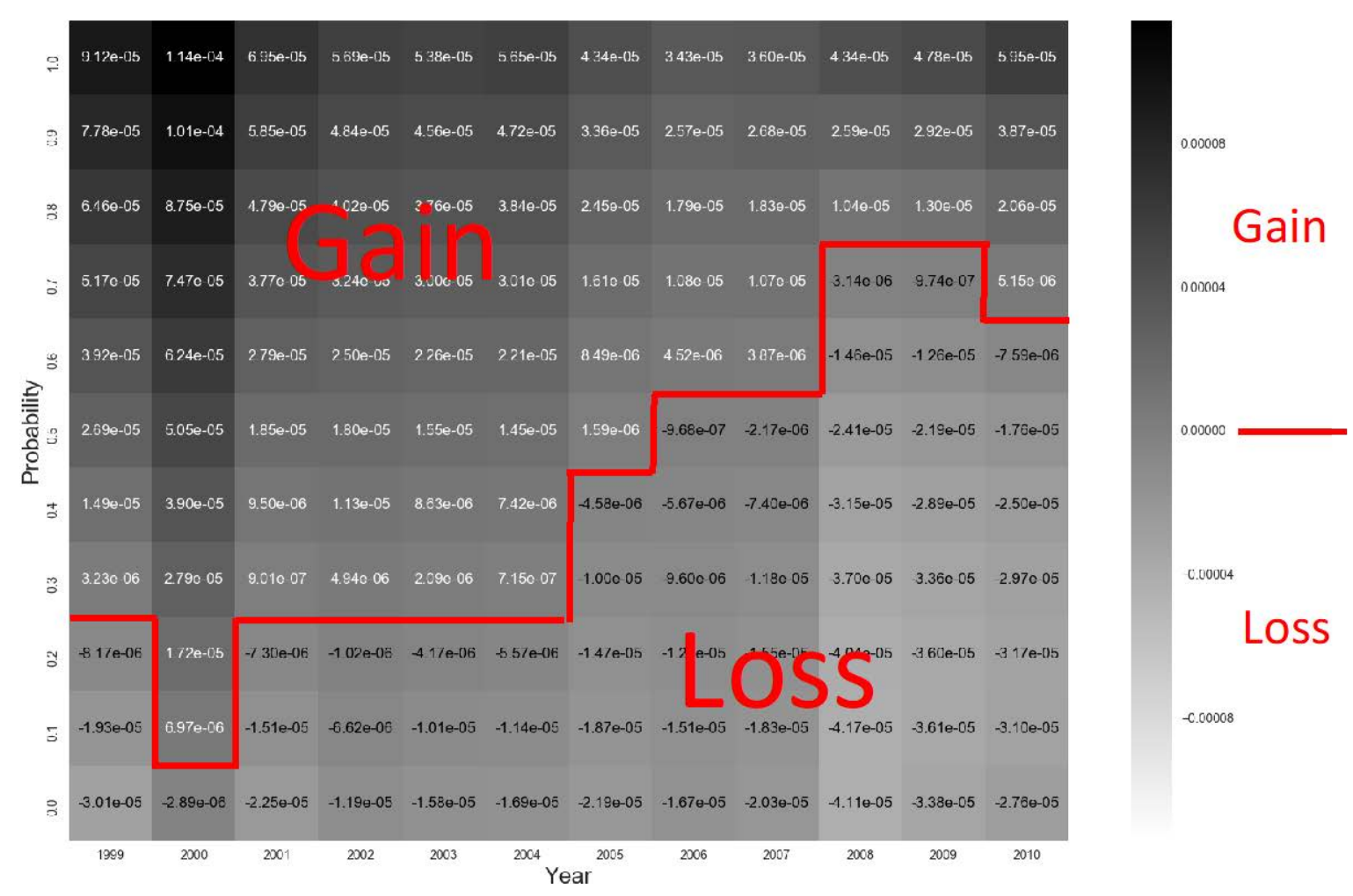

Figure 4 Expected returns for the currency pair of EUR/JPY: $\left(\mu_{\text {Year }}^{\text {NS,EUR/JPY }}\right) \square$ 


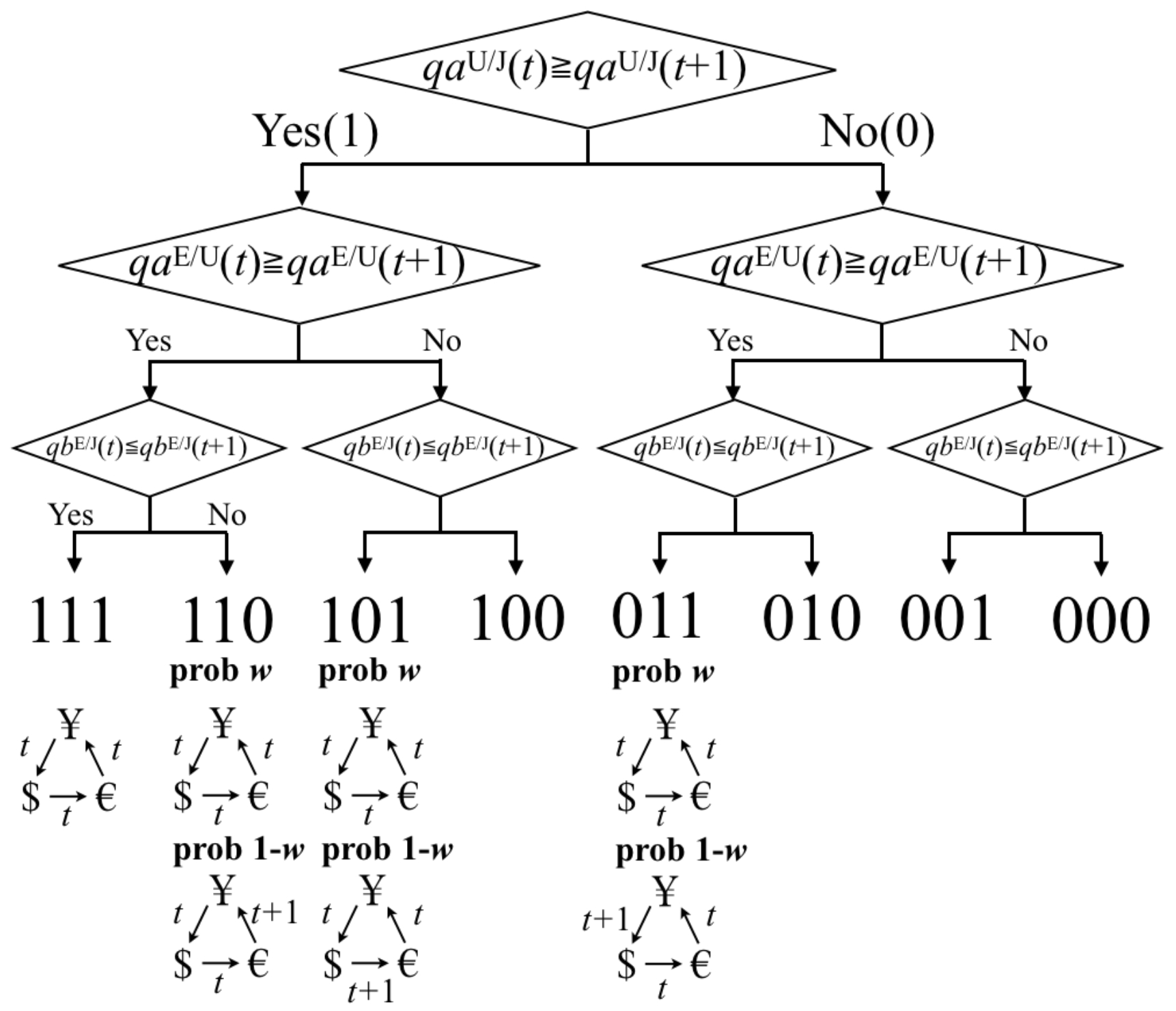

Figure 5 Flow chart of case 111,110,101,011,100,010,001,000 for (JPY-USD-EUR-JPY) 


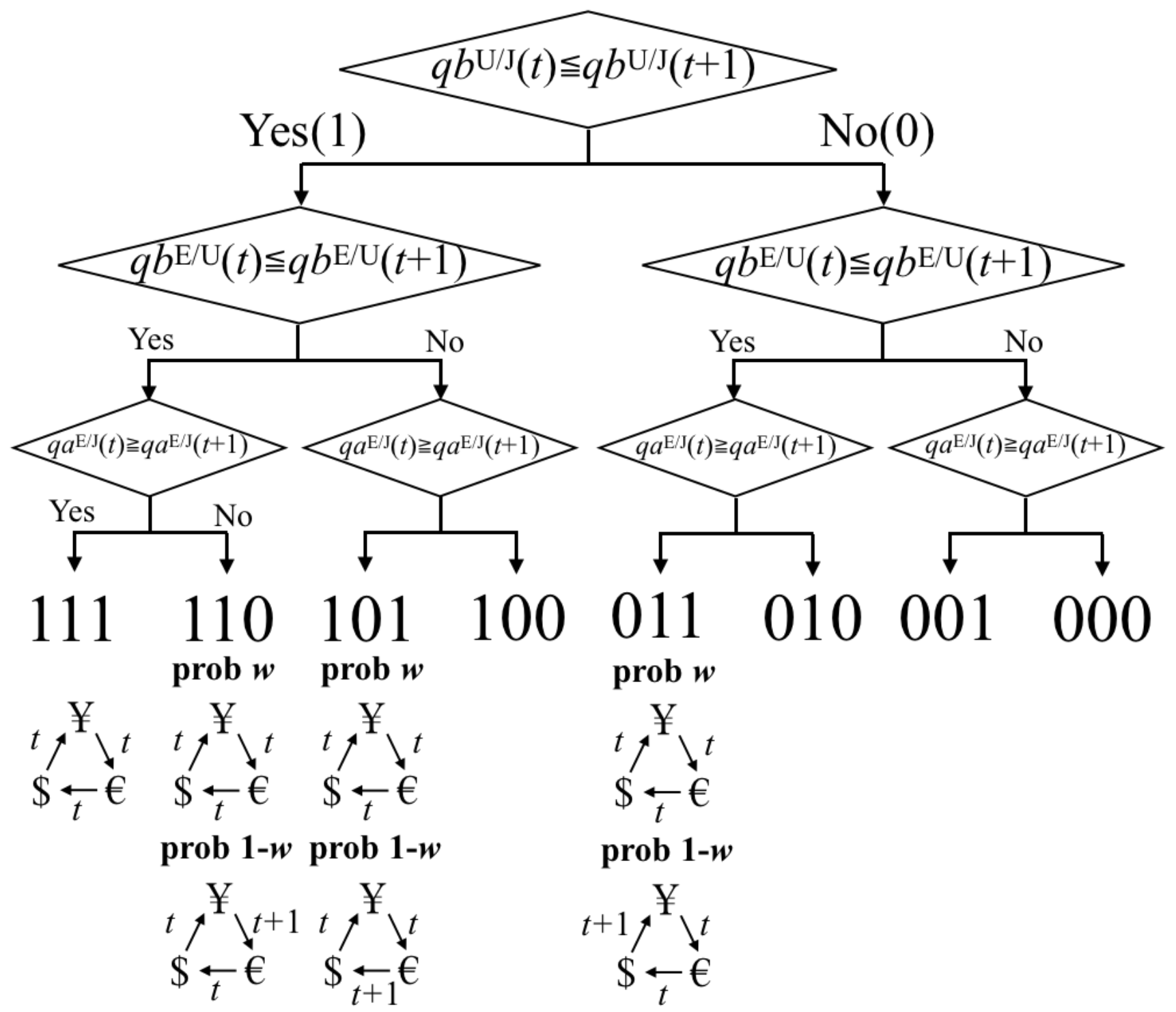

Figure 6 Flow chart of case 111,110,101,011,100,010,001,000 for (JPY-EUR-USD-JPY) 


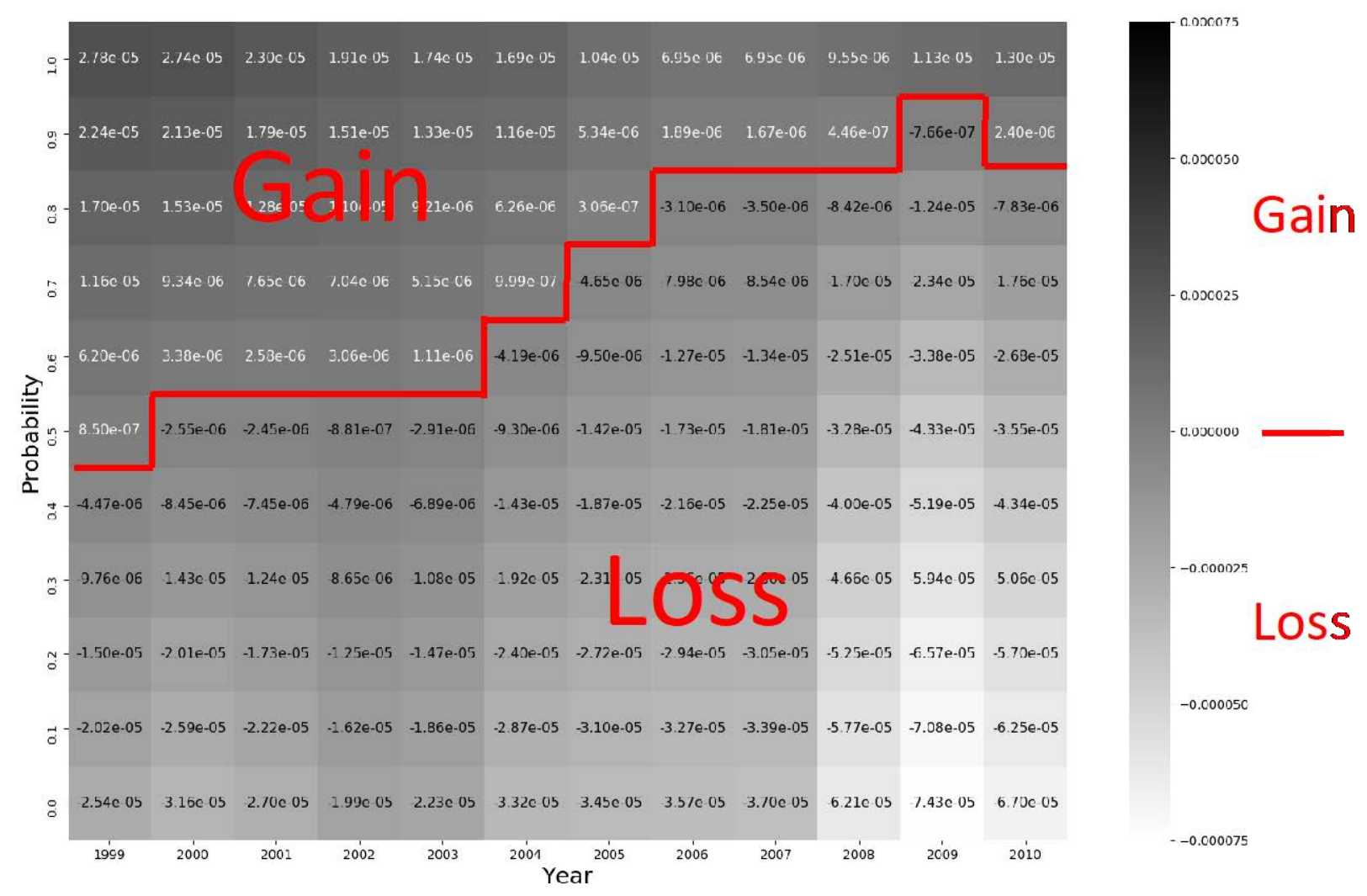

Figure 7E Average returns of Eastward triangular arbitrage with execution risk and transaction cost $\left(\mu_{\text {Year }}^{T A}\right)$. 


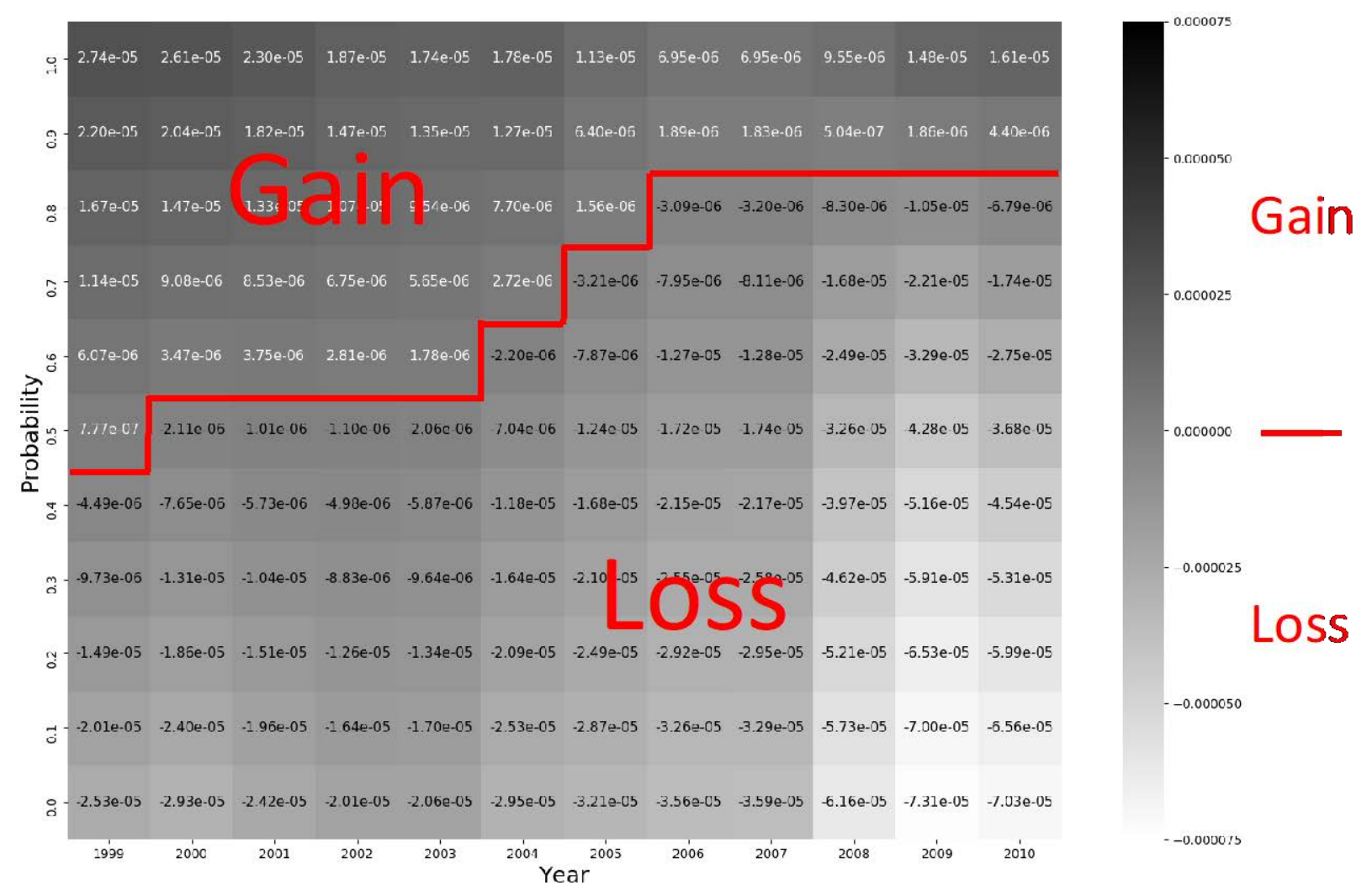

Figure 7W Average returns of Westward triangular arbitrage with execution risk and transaction cost $\left(\mu_{\text {Year }}^{T A}\right)$ 


\section{Tables}

Table 1

\begin{tabular}{|c|c|c|c|c|c|c|c|c|c|c|c|c|c|c|c|c|}
\hline \multirow[b]{2}{*}{ Year } & & \multicolumn{5}{|c|}{ USD/JPY } & \multicolumn{5}{|c|}{ EUR/USD } & \multicolumn{5}{|c|}{ EUR/JPY } \\
\hline & & 11 & 01 & 10 & 00 & Total & 11 & 01 & 10 & 00 & Total & 11 & 01 & 10 & 00 & Total \\
\hline \multirow{2}{*}{1999} & $\#(n)$ & 16,708 & 6,596 & 6,582 & 1,772 & 31,658 & 7,709 & 3,186 & 3,173 & 966 & 15,034 & 2,216 & 771 & 783 & 113 & 3,883 \\
\hline & $\%(p)$ & $52.8 \%$ & $20.8 \%$ & $20.8 \%$ & $5.6 \%$ & $100 \%$ & $51.3 \%$ & $21.2 \%$ & $21.1 \%$ & $6.4 \%$ & $100 \%$ & $57.1 \%$ & $19.9 \%$ & $20.2 \%$ & $2.9 \%$ & $100 \%$ \\
\hline \multirow{2}{*}{2000} & $\#(n)$ & 8,207 & 2,942 & 2,939 & 831 & 14,919 & 9,379 & 4,187 & 4,298 & 1,457 & 19,321 & 2,264 & 753 & 851 & 185 & 4,053 \\
\hline & $\%(p)$ & $55.0 \%$ & $19.7 \%$ & $19.7 \%$ & $5.6 \%$ & $100 \%$ & $48.5 \%$ & $21.7 \%$ & $22.2 \%$ & $7.5 \%$ & $100 \%$ & $55.9 \%$ & $18.6 \%$ & $21.0 \%$ & $4.6 \%$ & $100 \%$ \\
\hline \multirow{2}{*}{2001} & $\#(n)$ & 7,649 & 3,062 & 3,187 & 989 & 14,887 & 6,237 & 3,281 & 3,244 & 1,240 & 14,002 & 2,356 & 831 & 958 & 241 & 4,386 \\
\hline & $\%(p)$ & $51.4 \%$ & $20.6 \%$ & $21.4 \%$ & $6.6 \%$ & $100 \%$ & $44.5 \%$ & $23.4 \%$ & $23.2 \%$ & $8.9 \%$ & $100 \%$ & $53.7 \%$ & $18.9 \%$ & $21.8 \%$ & $5.5 \%$ & $100 \%$ \\
\hline \multirow{2}{*}{2002} & $\#(n)$ & 6,138 & 2,961 & 2,951 & 1,070 & 13,120 & 4,031 & 2,134 & 2,191 & 826 & 9,182 & 1,575 & 505 & 620 & 191 & 2,891 \\
\hline & $\%(p)$ & $46.8 \%$ & $22.6 \%$ & $22.5 \%$ & $8.2 \%$ & $100 \%$ & $43.9 \%$ & $23.2 \%$ & $23.9 \%$ & $9.0 \%$ & $100 \%$ & $54.5 \%$ & $17.5 \%$ & $21.4 \%$ & $6.6 \%$ & $100 \%$ \\
\hline \multirow{2}{*}{2003} & $\#(n)$ & 5,057 & 2,444 & 2,537 & 760 & 10,798 & 5,373 & 3,276 & 3,430 & 1,395 & 13,474 & 1,404 & 535 & 627 & 150 & 2,716 \\
\hline & $\%(p)$ & $46.8 \%$ & $22.6 \%$ & $23.5 \%$ & $7.0 \%$ & $100 \%$ & $39.9 \%$ & $24.3 \%$ & $25.5 \%$ & $10.4 \%$ & $100 \%$ & $51.7 \%$ & $19.7 \%$ & $23.1 \%$ & $5.5 \%$ & $100 \%$ \\
\hline \multirow{2}{*}{2004} & $\#(n)$ & 4,187 & 2,028 & 2,292 & 802 & 9,309 & 4,177 & 2,962 & 2,928 & 1,395 & 11,462 & 1,008 & 464 & 486 & 177 & 2,135 \\
\hline & $\%(p)$ & $45.0 \%$ & $21.8 \%$ & $24.6 \%$ & $8.6 \%$ & $100 \%$ & $36.4 \%$ & $25.8 \%$ & $25.5 \%$ & $12.2 \%$ & $100 \%$ & $47.2 \%$ & $21.7 \%$ & $22.8 \%$ & $8.3 \%$ & $100 \%$ \\
\hline \multirow{2}{*}{2005} & $\#(n)$ & 1,338 & 1,262 & 1,349 & 763 & 4,712 & 1,377 & 1,425 & 1,437 & 1,005 & 5,244 & 317 & 289 & 292 & 236 & 1,134 \\
\hline & $\%(p)$ & $28.4 \%$ & $26.8 \%$ & $28.6 \%$ & $16.2 \%$ & $100 \%$ & $26.3 \%$ & $27.2 \%$ & $27.4 \%$ & $19.2 \%$ & $100 \%$ & $28.0 \%$ & $25.5 \%$ & $25.7 \%$ & $20.8 \%$ & $100 \%$ \\
\hline \multirow{2}{*}{2006} & $\#(n)$ & 434 & 887 & 865 & 885 & 3,071 & 350 & 591 & 589 & 485 & 2,015 & 119 & 197 & 167 & 228 & 711 \\
\hline & $\%(p)$ & $14.1 \%$ & $28.9 \%$ & $28.2 \%$ & $28.8 \%$ & $100 \%$ & $17.4 \%$ & $29.3 \%$ & $29.2 \%$ & $24.1 \%$ & $100 \%$ & $16.7 \%$ & $27.7 \%$ & $23.5 \%$ & $32.1 \%$ & $100 \%$ \\
\hline \multirow{2}{*}{2007} & $\#(n)$ & 320 & 666 & 690 & 623 & 2,299 & 145 & 291 & 310 & 250 & 996 & 172 & 372 & 376 & 431 & 1,351 \\
\hline & $\%(p)$ & $13.9 \%$ & $29.0 \%$ & $30.0 \%$ & $27.1 \%$ & $100 \%$ & $14.6 \%$ & $29.2 \%$ & $31.1 \%$ & $25.1 \%$ & $100 \%$ & $12.7 \%$ & $27.5 \%$ & $27.8 \%$ & $31.9 \%$ & $100 \%$ \\
\hline \multirow{2}{*}{2008} & $\#(n)$ & 346 & 710 & 786 & 1,108 & 2,950 & 304 & 1,024 & 1,004 & 1,318 & 3,650 & 138 & 360 & 378 & 676 & 1,552 \\
\hline & $\%(p)$ & $11.7 \%$ & $24.1 \%$ & $26.6 \%$ & $37.6 \%$ & $100 \%$ & $8.3 \%$ & $28.1 \%$ & $27.5 \%$ & $36.1 \%$ & $100 \%$ & $8.9 \%$ & $23.2 \%$ & $24.4 \%$ & $43.6 \%$ & $100 \%$ \\
\hline \multirow{2}{*}{2009} & $\#(n)$ & 50 & 227 & 245 & 437 & 959 & 90 & 396 & 435 & 883 & 1,804 & 29 & 115 & 113 & 284 & 541 \\
\hline & $\%(p)$ & $5.2 \%$ & $23.7 \%$ & $25.5 \%$ & $45.6 \%$ & $100 \%$ & $5.0 \%$ & $22.0 \%$ & $24.1 \%$ & $48.9 \%$ & $100 \%$ & $5.4 \%$ & $21.3 \%$ & $20.9 \%$ & $52.5 \%$ & $100 \%$ \\
\hline \multirow{2}{*}{2010} & $\#(n)$ & 29 & 51 & 65 & 84 & 229 & 41 & 124 & 140 & 184 & 489 & 16 & 38 & 32 & $\begin{array}{l}107 \\
\end{array}$ & 193 \\
\hline & $\%(p)$ & $12.7 \%$ & $22.3 \%$ & $28.4 \%$ & \begin{tabular}{l|l}
$36.7 \%$ \\
\end{tabular} & $100 \%$ & $8.4 \%$ & $25.4 \%$ & $28.6 \%$ & $37.6 \%$ & $100 \%$ & $8.3 \%$ & $19.7 \%$ & $16.6 \%$ & $55.4 \%$ & $100 \%$ \\
\hline
\end{tabular}

Notes: (1) Row "\#"is the number of negative spread cases (in units of seconds) that appeared in the year by types of execution success or failures of the two legs. (2) "\%” shows the percentage of the number of the particular combination(s) of execution in ratio to total cases.

Table 2 Average returns of Cases 11, 01, 10 for each sample year

\begin{tabular}{|r|r|r|r|r|r|r|r|r|r|}
\hline & \multicolumn{3}{|c|}{ USD/JPY } & \multicolumn{1}{c|}{ EUR/USD } & \multicolumn{3}{c|}{ EUR/JPY } \\
\hline Year & \multicolumn{1}{|c|}{11} & \multicolumn{1}{c|}{01} & \multicolumn{1}{c|}{10} & \multicolumn{1}{c|}{11} & \multicolumn{1}{c|}{01} & \multicolumn{1}{c|}{10} & \multicolumn{1}{c|}{11} & \multicolumn{1}{c|}{01} & \multicolumn{1}{c|}{10} \\
\hline 1999 & 1.000124 & 0.999875 & 0.999876 & 1.000117 & 0.999911 & 0.999914 & 1.000216 & 0.999546 & 0.999521 \\
\hline 2000 & 1.000122 & 0.999891 & 0.999885 & 1.000135 & 0.999899 & 0.999899 & 1.000269 & 0.999592 & 0.999641 \\
\hline 2001 & 1.000108 & 0.999893 & 0.999896 & 1.000129 & 0.9999 & 0.999901 & 1.000166 & 0.999681 & 0.999657 \\
\hline 2002 & 1.000107 & 0.999908 & 0.999906 & 1.00012 & 0.999913 & 0.999917 & 1.000137 & 0.999769 & 0.999739 \\
\hline 2003 & 1.00011 & 0.999901 & 0.999894 & 1.000103 & 0.999924 & 0.999922 & 1.00013 & 0.999778 & 0.999765 \\
\hline 2004 & 1.000112 & 0.999892 & 0.999886 & 1.000093 & 0.999917 & 0.999925 & 1.000136 & 0.999751 & 0.999809 \\
\hline 2005 & 1.000102 & 0.999907 & 0.999898 & 1.000091 & 0.999924 & 0.999939 & 1.000106 & 0.999853 & 0.999853 \\
\hline 2006 & 1.000092 & 0.999921 & 0.999919 & 1.000088 & 0.999934 & 0.999928 & 1.000085 & 0.999907 & 0.999903 \\
\hline 2007 & 1.000096 & 0.99991 & 0.999916 & 1.000086 & 0.999929 & 0.99993 & 1.000089 & 0.999897 & 0.999908 \\
\hline 2008 & 1.000124 & 0.999838 & 0.999841 & 1.000084 & 0.999898 & 0.999891 & 1.000106 & 0.99982 & 0.999758 \\
\hline 2009 & 1.000123 & 0.999822 & 0.999833 & 1.000091 & 0.999903 & 0.99989 & 1.000116 & 0.999787 & 0.999828 \\
\hline 2010 & 1.000137 & 0.999764 & 0.999802 & 1.000136 & 0.999884 & 0.999879 & 1.000143 & 0.999841 & 0.99975 \\
\hline
\end{tabular}


Table 3E The number of Occurrence and the probability for Eastward by Cases $\{\mathrm{x}, \mathrm{y}, \mathrm{z}\}$

\begin{tabular}{|c|c|c|c|c|c|c|c|c|c|c|}
\hline Year & & 111 & 110 & 101 & 011 & 100 & 010 & 001 & $\mathrm{P} 000$ & Total \\
\hline \multirow{2}{*}{1999} & (n) & 32,124 & 7,854 & 3,629 & 4,900 & 786 & 1,162 & 515 & 116 & 51,08 \\
\hline & $\%(\mathrm{p})$ & $62.9 \%$ & $15.4 \%$ & $7.1 \%$ & $9.6 \%$ & $1.5 \%$ & $2.3 \%$ & $1.0 \%$ & $0.2 \%$ & $100 \%$ \\
\hline \multirow{2}{*}{2000} & $\#(n)$ & 32,977 & 9,885 & 4,368 & 3,888 & 1,253 & 1,236 & 490 & 137 & \\
\hline & $\%(\mathrm{p})$ & $60.8 \%$ & $18.2 \%$ & $3.1 \%$ & $7.2 \%$ & $2.3 \%$ & $2.3 \%$ & $0.9 \%$ & $0.3 \%$ & 100 \\
\hline \multirow{2}{*}{2001} & $\#(n)$ & 33,553 & 10,941 & 4,806 & 4,959 & 1,498 & 1,576 & 694 & 213 & 8,24 \\
\hline & $\%(\mathrm{p})$ & $57.6 \%$ & $18.8 \%$ & $8.3 \%$ & $8.5 \%$ & $2.6 \%$ & $2.7 \%$ & $1.2 \%$ & $0.4 \%$ & 100 \\
\hline \multirow{2}{*}{2002} & $\#(n)$ & 26,011 & 7,892 & 3,812 & 5,247 & 1,084 & 1,613 & 721 & 217 & 46,59 \\
\hline & $\%(\mathrm{p})$ & $55.8 \%$ & $16.9 \%$ & $8.2 \%$ & $11.3 \%$ & $2.3 \%$ & $3.5 \%$ & $1.5 \%$ & $0.5 \%$ & $100^{\circ}$ \\
\hline \multirow{2}{*}{2003} & $\#(n)$ & 31,645 & 10,961 & 5,386 & 6,191 & 1,831 & 2,219 & 1,121 & 368 & 59,72 \\
\hline & $\%(\mathrm{p})$ & 53.0 & 18.4 & $9.0 \%$ & $10.4 \%$ & $3.1 \%$ & $3.7 \%$ & $1.9^{\circ}$ & $0.6 \%$ & 100 \\
\hline \multirow{2}{*}{2004} & $\#(n)$ & 25,7 & 12,7 & 5,2 & 6,618 & 2,6 & $\begin{array}{r}3,704 \\
\end{array}$ & 1,463 & 807 & 0 \\
\hline & $\%(\mathrm{p})$ & 43. & & & & & & & & \\
\hline \multirow{2}{*}{2005} & $\#(n)$ & 13,8 & $10, \varepsilon$ & & & & & & & \\
\hline & $\%(\mathrm{p})$ & 30.4 & & & & & & & & 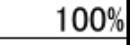 \\
\hline \multirow{2}{*}{2006} & $\#(n)$ & & & & & & & & & 9 \\
\hline & $\%(\mathrm{p})$ & 24.0 & 24. & 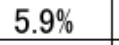 & 11.7 & 7.8 & & 3.7 & & 10 \\
\hline \multirow{2}{*}{2007} & $\#(n)$ & 7,94 & 10,9 & 2,0 & $4,8:$ & 3,3 & & 1,79 & 2,395 & 40.20 \\
\hline & $\%(\mathrm{p})$ & $19.7 \%$ & $27.2 \%$ & $5.1 \%$ & 12.1 & 8.3 & 17.1 & $4.5^{\circ}$ & 6.0 & 100 \\
\hline \multirow{2}{*}{2008} & $\#(n)$ & 5,469 & 7,580 & 2,333 & 4,768 & 3,95 & 6,550 & $\begin{array}{r}3,026 \\
\end{array}$ & 3,056 & 36,73 \\
\hline & $\%(\mathrm{p})$ & $14.9 \%$ & $20.6 \%$ & $6.4 \%$ & $13.0 \%$ & $10.8 \%$ & $17.8 \%$ & $8.2 \%$ & $8.3 \%$ & 100 \\
\hline \multirow{2}{*}{2009} & \#(n) & 1,326 & 2,496 & 830 & 1,310 & 1,70 & 2,440 & 1,223 & 1,753 & 13,08 \\
\hline & $\%(\mathrm{p})$ & $10.1 \%$ & 19.1 & $6.3 \%$ & $10.0 \%$ & $13.1 \%$ & $18.6 \%$ & $9.3 \%$ & $13.4 \%$ & 100 \\
\hline \multirow{2}{*}{2010} & \#(n) & & & & 548 & 628 & 938 & 452 & 472 & 5,08 \\
\hline & $\%(p)$ & $11.0 \%$ & $23.0 \%$ & $6.3 \%$ & $10.8 \%$ & $12.3 \%$ & $18.4 \%$ & $8.9 \%$ & $9.3 \%$ & $100^{\circ}$ \\
\hline
\end{tabular}

Table 3W The number of Occurrence and the probability for Eastward by Cases $\{\mathrm{x}, \mathrm{y}, \mathrm{z}\}$

\begin{tabular}{|c|c|c|c|c|c|c|c|c|c|c|}
\hline Year & & 111 & 110 & 101 & 011 & 100 & 010 & 001 & 000 & Total \\
\hline \multirow{2}{*}{1999} & & 29,290 & 6,947 & 3,334 & 4,533 & 734 & 985 & 487 & 103 & 46,413 \\
\hline & $\%(p)$ & $63.1 \%$ & $15.0 \%$ & $7.2 \%$ & $9.8 \%$ & $1.6 \%$ & $2.1 \%$ & $1.0 \%$ & $0.2 \%$ & $100 \%$ \\
\hline \multirow{2}{*}{2000} & $\#(n)$ & 28,754 & 037 & ,161 & 3,623 & ,168 & 1,112 & 498 & 145 & \\
\hline & $\%(\mathrm{p})$ & $59.3 \%$ & $18.6 \%$ & $6 \%$ & $7.5 \%$ & $2.4 \%$ & $2.3 \%$ & $1.0 \%$ & $0.3 \%$ & $100 \%$ \\
\hline \multirow{2}{*}{2001} & $\#(n)$ & 30,030 & 9,707 & 4,667 & 4,538 & 1,411 & 1,444 & 705 & 201 & 52,70 \\
\hline & $\%(\mathrm{p})$ & $57.0 \%$ & $18.4 \%$ & $8.9 \%$ & $8.6 \%$ & $2.7 \%$ & $2.7 \%$ & $1.3 \%$ & $0.4 \%$ & 100 \\
\hline \multirow{2}{*}{2002} & $\#(n)$ & 22,959 & 7,188 & 3,423 & 4,770 & 962 & 1,511 & 734 & 18 & 1,73 \\
\hline & $\%(\mathrm{p})$ & $55.0 \%$ & $17.2 \%$ & $8.2 \%$ & $11.4 \%$ & $2.3 \%$ & $3.6 \%$ & $1.8 \%$ & $0.4 \%$ & $100 \%$ \\
\hline \multirow{2}{*}{2003} & $\#(n)$ & 26,370 & 8,660 & $\begin{array}{r}4,758 \\
\end{array}$ & 5,645 & 1,550 & 1,899 & 966 & 316 & 50,164 \\
\hline & $\%(\mathrm{p})$ & $52.6 \%$ & $17.3 \%$ & $9.5 \%$ & 11.3 & $3.1 \%$ & $3.8 \%$ & $1.9 \%$ & $0.6 \%$ & 100 \\
\hline \multirow{2}{*}{2004} & $\#(n)$ & 23,70 & 1,447 & $\begin{array}{r}5,016 \\
\end{array}$ & & 2,5 & 3,4 & 1,443 & 843 & 54,992 \\
\hline & $\%(p)$ & 43. & 2 & 9.1 & & & & & & 100 \\
\hline \multirow{2}{*}{2005} & $\#(n)$ & 14, & 11,6 & & & & & 1,537 & & 8,413 \\
\hline & $\%(\mathrm{p})$ & 30.8 & 24. & 6.70 & 12. & 6.0 & 13. & & & $100 \%$ \\
\hline \multirow{2}{*}{2006} & $\#(n)$ & & 10, & & & & & & & 39,917 \\
\hline & $\%(\mathrm{p})$ & 22.6 & 25. & $5.9 \%$ & 11. & 7.9 & 17. & & & 100 \\
\hline \multirow{2}{*}{2007} & $\#(n)$ & 8,0 & 11,2 & 2,1 & & & & 1,711 & & 1,45 \\
\hline & $\%(p)$ & 19.4 & 27.1 & $5.2 \%$ & 12. & 88 & 17. & & & 100 \\
\hline \multirow{2}{*}{2008} & $\#(n)$ & 5,029 & 7,82 & 2,304 & 4,67 & 4,2 & 6,724 & 2,922 & & 36,791 \\
\hline & $\%(\mathrm{p})$ & 13.7 & 21.3 & $6.3 \%$ & $12.7 \%$ & 11.4 & 18. & 7.9 & 8.4 & 100 \\
\hline \multirow{2}{*}{2009} & $\#(n)$ & 153 & 2,37 & 662 & 1,136 & 1,67 & 2,434 & 1,136 & 1,883 & 12,459 \\
\hline & $\%(\mathrm{p})$ & $9.3 \%$ & $19.1 \%$ & $5.3 \%$ & $9.1 \%$ & $13.5 \%$ & $19.5 \%$ & $9.1 \%$ & $15.1 \%$ & $100 \%$ \\
\hline \multirow{2}{*}{2010} & $\#(n)$ & 47 & 95 & 275 & 418 & 576 & 897 & 406 & 429 & 4,424 \\
\hline & $\%(\mathrm{p})$ & $10.7 \%$ & $21.5 \%$ & $6.2 \%$ & $9.4 \%$ & $13.0 \%$ & $20.3 \%$ & $9.2 \%$ & $9.7 \%$ & $100 \%$ \\
\hline
\end{tabular}


Table 4E Annual average returns of Eastward triangular arbitrage

\begin{tabular}{|c|c|c|c|c|c|c|c|}
\hline Year & 111 & 110 & 101 & 011 & 100 & 010 & 001 \\
\hline 1999 & 1.000073 & 0.999597 & 0.999958 & 0.999911 & 0.999494 & 0.999472 & 0.999792 \\
\hline 2000 & 1.000072 & 0.999608 & 0.999928 & 0.999928 & 0.999479 & 0.999496 & 0.999811 \\
\hline 2001 & 1.000062 & 0.999716 & 0.999925 & 0.999928 & 0.999609 & 0.999601 & 0.999807 \\
\hline 2002 & 1.000053 & 0.999807 & 0.999932 & 0.999927 & 0.999701 & 0.999703 & 0.999818 \\
\hline 2003 & 1.000049 & 0.999823 & 0.999944 & 0.999925 & 0.999706 & 0.999706 & 0.999829 \\
\hline 2004 & 1.000048 & 0.999811 & 0.999951 & 0.999921 & 0.999734 & 0.999709 & 0.999834 \\
\hline 2005 & 1.000033 & 0.999893 & 0.999949 & 0.999929 & 0.999814 & 0.999794 & 0.999848 \\
\hline 2006 & 1.000025 & 0.999910 & 0.999945 & 0.999932 & 0.999835 & 0.999824 & 0.999858 \\
\hline 2007 & 1.000025 & 0.999913 & 0.999950 & 0.999927 & 0.999851 & 0.999837 & 0.999857 \\
\hline 2008 & 1.000031 & 0.999831 & 0.999936 & 0.999894 & 0.999766 & 0.999751 & 0.999794 \\
\hline 2009 & 1.000035 & 0.999794 & 0.999926 & 0.999877 & 0.999726 & 0.999710 & 0.999778 \\
\hline 2010 & 1.000039 & 0.999828 & 0.999927 & 0.999882 & 0.999773 & 0.999746 & 0.999789 \\
\hline
\end{tabular}

Table 4W Annual average returns of Westward triangular arbitrage

\begin{tabular}{|c|c|c|c|c|c|c|c|}
\hline Year & 111 & 110 & 101 & 011 & 100 & 010 & 001 \\
\hline 1999 & 1.000072 & 0.999598 & 0.999952 & 0.999910 & 0.999478 & 0.999439 & 0.999803 \\
\hline 2000 & 1.000069 & 0.999658 & 0.999926 & 0.999922 & 0.999555 & 0.999534 & 0.999790 \\
\hline 2001 & 1.000062 & 0.999748 & 0.999927 & 0.999926 & 0.999634 & 0.999627 & 0.999794 \\
\hline 2002 & 1.000052 & 0.999818 & 0.999934 & 0.999926 & 0.999700 & 0.999708 & 0.999817 \\
\hline 2003 & 1.000049 & 0.999836 & 0.999944 & 0.999926 & 0.999724 & 0.999721 & 0.999830 \\
\hline 2004 & 1.000050 & 0.999840 & 0.999949 & 0.999919 & 0.999750 & 0.999727 & 0.999828 \\
\hline 2005 & 1.000035 & 0.999906 & 0.999949 & 0.999927 & 0.999829 & 0.999803 & 0.999847 \\
\hline 2006 & 1.000025 & 0.999915 & 0.999946 & 0.999930 & 0.999838 & 0.999832 & 0.999860 \\
\hline 2007 & 1.000025 & 0.999920 & 0.999951 & 0.999927 & 0.999854 & 0.999842 & 0.999858 \\
\hline 2008 & 1.000031 & 0.999845 & 0.999933 & 0.999890 & 0.999771 & 0.999756 & 0.999800 \\
\hline 2009 & 1.000043 & 0.999807 & 0.999917 & 0.999873 & 0.999733 & 0.999712 & 0.999784 \\
\hline 2010 & 1.000046 & 0.999816 & 0.999927 & 0.999882 & 0.999760 & 0.999745 & 0.999777 \\
\hline
\end{tabular}

